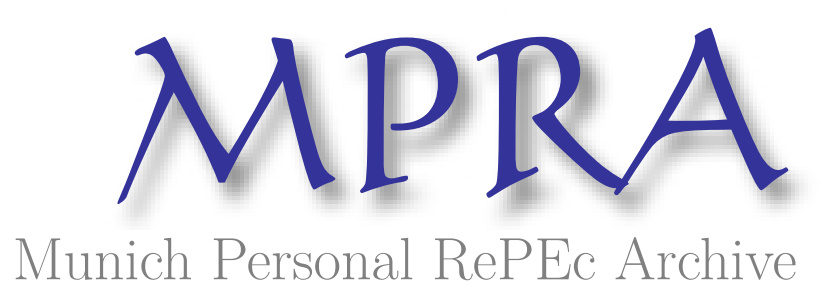

\title{
Cost Versus Control: Understanding Ownership Through Outsourcing in Hospitals
}

Dalton, Christina Marsh and Warren, Patrick L.

Wake Forest University, Clemson University

16 May 2014

Online at https://mpra.ub.uni-muenchen.de/68495/

MPRA Paper No. 68495, posted 23 Dec 2015 06:11 UTC 


\title{
Cost versus Control: Understanding Ownership Through Outsourcing in Hospitals.
}

\author{
Christina Marsh Dalton* Patrick L. Warren ${ }^{\dagger}$
}

December 4, 2015

\begin{abstract}
For-profit hospitals in California contract out services much more intensely than either private nonprofit or public hospitals. To explain why, we build a model in which the outsourcing decision is a trade-off between net revenues and some non-monetary benefit to the manager, or "bias" in the manner of production. Since nonprofit firms must consume profits under restrictions, they trade off bias and income differently than forprofit firms. This difference is exaggerated in services where the benefits of controlling the details of production are particularly important but minimized when firms are hit with a fixed-cost shock. We test these predictions in a panel of California hospitals, finding evidence for each. These results suggest that a model of public or nonprofit make-or-buy decisions should be more than a simple relabeling of a model derived in the for-profit context.
\end{abstract}

JEL Classification: I11, L24, L33

Keywords: Hospitals, Make-or-Buy, Public versus Private, Nonprofit Firm Behavior

\footnotetext{
*Wake Forest University, 204B Kirby Hall, Winston-Salem, NC 27109. Email: tina.marsh.dalton@gmail.com

${ }^{\dagger}$ John E. Walker Department of Economics, Clemson University, 222 Sirrine Hall, Clemson, SC 29634. E-mail: patrick.lee.warren@gmail.com. We have received very useful feedback from Tom Chang, Mireille Jacobson, Richard Lindrooth, Jens Prufer, Michael Vlassopoulos and seminar participants at Appalachian State University, the Department of Justice, Clemson IO Workshop, UNC Chapel Hill, University of South Carolina, SEA2012, ISNIE/ESNIE 2012, and ASSA 2013.
} 
If you want a thing done well, do it yourself. - Napoleon Bonaparte

\section{Introduction}

An important decision faced by any major organization is which activities it will engage in itself and which it will outsource to some outside provider. While the choice of a forprofit firm to outsource rather than provide services directly is (relatively) well-understood (Lafontaine and Slade 2007), little is known about how nonprofit and public firms make these decisions. The outsourcing decision provides insight into the nonprofit sector, in particular, because the nonprofit may be ceding control to a firm less likely to share its mission. Research on hospital ownership often treats all service provision as within the firm, but rising costs make outsourcing attractive in the health care industry. In this paper, we analyze the makeor-buy decisions of public, nonprofit, and for-profit California hospitals, demonstrate robust differences among ownership types, and provide both a theoretically-grounded explanation for these ownership differences and tests of the proposed mechanism.

For-profit, nonprofit, and public hospitals in California vary significantly in the extent to which they outsource service provision. During 1996-2008, for-profit short-term generalcare hospitals in California outsourced 25.7 percent of the non-physician costs of an average service to outside providers. ${ }^{1}$ Nonprofits outsourced much less, 18.9 percent of the nonphysician costs of an average service, across a range of both medical and administrative services. Balakrishnan, Eldenburg, Krishnan and Soderstrom (2010) show that these differences in average outsourcing rates are robust to a number of controls for hospital and market characteristics. Given the size of the hospital industry and continued health expenditure growth, these outsourcing levels are also economically important.

To analyze the differences in outsourcing among ownership types, we extend a well-known model of nonprofit entrepreneurship by Glaeser and Shleifer (2001) to include an outsourcing decision. We assume that managers not only place value on net revenues (profits) but also place some value on controlling the exact manner in which a service is performed, either for their own intrinsic reasons, organizational incentives, or due to influence from some interest group (e.g. elite workers) who have preferences about how the service is performed. When outsourcing is cheaper, control must be balanced against cost-minimization. Does a manager want more control or lower costs? In our model, managers in nonprofit firms are restricted in how they can use excess revenue (spending must be consistent with the hospital's nonprofit

\footnotetext{
${ }^{1}$ The outsourcing rate is roughly defined as the percent of the total direct costs of a service which are from contracts with outside service providers. This is fully defined in Section 3.
} 
justification), and this restriction induces them to put different weights on these two characteristics than for-profit managers do. Since, all else equal, a marginal unrestricted dollar of excess revenues has higher value than a restricted dollar, outsourcing is more attractive to managers of for-profit firms than similarly-situated nonprofit firms whenever the outside producer has a comparative advantage in low-cost and low-control production. These outsourcing differences are amplified when control over the manner of production is particularly important and dampened when a fixed-cost shock lowers net incomes.

We test these predictions on a rich dataset of California hospitals with service-specific outsourcing measures and market characteristics over the period 1996-2008. For-profits outsource consistently more than private nonprofits, and public hospitals outsource even less than private nonprofits. These results are robust to the inclusion of controls for hospital size and scope, service-specific output, presence of a residency program, market characteristics, as well as service, year, and county fixed effects.

To investigate the importance of control, we divide hospital services into classes of differential managerial concern. For example, if elite workers are influential, controlling the manner of production in physician-intensive services like cardiology or emergency services may be more important, as compared to services that have little or no physician labor, like groundskeeping or parking. We also highlight labor-intensive services, since control of these services may be salient for public managers. We classify services as labor/physician intense by measuring the share of physician or labor costs as a percent of total direct costs within that service. Our prediction is that outsourcing differences should be most marked for services where control is particularly important to the manager. In line with this prediction, outsourcing differences between private nonprofits and for-profits are much bigger for physician-intensive services, while there is no significant difference for non-physicianintensive services. Public hospitals, by contrast, consistently outsource less than for-profits across both of these service classes. The pattern for labor-intensive services, however, is quite different. Labor intensity has no relationship with the private nonprofit outsourcing rates, but public hospitals outsource labor-intensive services much less than similarly-situated forprofits (or private nonprofits). Control of labor-intensive services is particularly important to public managers, but not to private nonprofit managers, which is exactly what our model predicts.

The model's third prediction is that a fixed-cost shock should cause nonprofits to look more like for-profits in their outsourcing decisions. We test this prediction by taking advantage of California's seismic retrofitting requirements, which hit different hospitals with very different retrofitting cost shocks depending on their local geography. Nonprofit and public hospitals that experience greater fixed-cost shocks outsource at rates similar to for-profits. 
Nonprofit and public hospitals persist in less outsourcing only if they experience relatively small fixed-cost shocks. This prediction is also complementary with the importance of control, in that the convergence of nonprofit and for-profit outsourcing rates for big fixed-cost shocks is most evident in physician-intensive and labor-intensive services.

This paper contributes to two literatures. There is a burgeoning literature on the "boundary of the organization" and how public entities provide services (Hart, Shleifer and Vishny 1997, Lopez de Silanes, Shleifer and Vishny 1997, Nelson 1997, Brown and Potoski 2003, Martimort and Pouyet 2008, David and Chiang 2009, Levin and Tadelis 2010, Iossa and Martimort 2012), but nearly every empirical investigation has focused on one ownership type. These studies cannot address what is essentially "public" or "nonprofit" about choices because they lack a control group of profit maximizers. Instead, they are comparative static in nature, analyzing how organizations adjust to changes in the economic or political environment. An important contribution of our work is that we can, first, identify divergence in outsourcing decisions among ownership types in the cross-section, and second, compare these differences across services and see how these differences respond to comparative static changes. Hospitals are a particularly apt organization to investigate, because the organizational forms span for-profit, private nonprofit, and various sorts of publicly-operated institutions. A handful of papers have taken advantage of this diversity. Coles and Hesterly (1998) touch on nonprofit and for-profit differences, but focus on how transaction costs influence which hospital services are outsourced. Balakrishnan et al. (2010) describe outsourcing differentials at the level of the hospital. We take their correlations as motivation, show that the large differences by ownership type are robust within services, and show that those differences are consistent with a model in which nonprofits are induced by nondistribution constraints to trade-off costs versus control at a different rate than for-profit firms do.

Second, there is a significant literature on the effects of nonprofit status on the behavior of firms, in general, and hospitals, in particular. ${ }^{2}$ Sloan (2000) summarizes the particular effects present in the hospital context due to moral hazard and the consumer's asymmetric information. This literature is particularly concerned with the effect of ownership on the provision of service quality (Sloan et al. 2001, Picone et al. 2002, Eggleston et al. 2008), but also on the role of competition (Duggan 2002), managerial compensation (Ballou and Weisbrod 2003), and these characteristics combined with the question of what drives nonprofit behavior, more generally (Deneffe and Masson 2002, Horwitz and Nichols 2009, Chang and Jacobson 2011, McClellan and Staiger 2000). The paper most related to ours, both in context and approach, is Chang and Jacobson (2011), which looks at hospitals in California

\footnotetext{
${ }^{2}$ For a nice synthetic summary of the general issue of nonprofit behavior, see Malani, Philipson and David (2003).
} 
and also uses seismic retrofitting as an exogenous cost shock. While they are concerned with the question of what nonprofits "maximize," we have a much more specific goal of looking at one aspect of the production decision, outsourcing, to highlight an important difference in the way nonprofit firms conduct their affairs. We focus on outsourcing as a component of total production, but this is particularly relevant for answering the question of how mission and production decisions are made differently by ownership type. Outsourcing can have real effects on mission if there are significant elements of the service that are difficult to fully specify in the contract. We see our work as complementary to the literature, where (to use their terminology) we identify an additional dimension along which "perquisite-maximizing" nonprofits differ from their "profit-maximizing" kin.

The rest of the paper proceeds as follows. Section 2 presents a model of nonprofit and for-profit outsourcing behavior. Section 3 describes California hospital ownership types, our data, and intensive-service measures. Section 4 describes the econometric specification and discusses our results on outsourcing, control, and fixed cost shocks. We have a brief discussion of alternative explanations in Section 5 before concluding in Section 6 .

\section{A Model of Outsourcing}

Consider a model of nonprofit behavior that borrows heavily from Glaeser and Shleifer (2001) but adds an outsourcing decision. We model the firm's decisions about production and outsourcing as controlled by a unitary actor, who we refer to as the manager. Assume the firm's manager solves

$$
\max _{n, q, b} u(n, q, b \mid \rho)=n+v(q)+\rho b
$$

subject to

$$
\begin{gathered}
q+n \leq I(b)-F, \\
n \leq 0 \text { for nonprofits, }
\end{gathered}
$$

where the manager maximizes over qualifying spending $(q)$, non-qualifying spending $(n)$, and production bias $(b)$. The difference between qualifying and non-qualifying spending captures how nonprofits and for-profits spend excess revenues (profits) differently. Qualifying spending is interpreted broadly as anything that can be purchased with excess revenues without violating the rules governing nonprofit behavior. It might include, for example, uncompen-

sated care, an improved physical working environment of the manager or employees, or more generous benefits. Non-qualifying spending includes all other goods on which a manager 
could spend excess revenues, including things barred to the nonprofit manager, like taking these excess revenues home as profits or distributing them to shareholders. Returns to qualifying spending, $v(q)$, are increasing and concave, so qualifying spending is always valuable but has diminishing marginal returns. Non-qualifying spending, by contrast, is assumed to have a constant marginal value. This constant return to non-qualifying spending is just a modelling convenience. All we really require is that the marginal value of an additional dollar decreases more quickly when the scope of spending is restricted. Nonprofits are constrained to avoid non-qualifying spending, so nonprofits must consume all net revenues as qualifying spending, $q{ }^{3}$ Denote by $\bar{q}$ the level of spending where the marginal value of qualifying spending passes below that of non-qualifying spending (i.e., where $v^{\prime}(\bar{q})=1$ ).

A manager may decrease the revenues available to spend by increasing production bias, $b$. Production bias captures the degree of deviation in production from the perfect profitmaximizing manner for the given service. As a normalization, let $b=0$ represent the profit-maximizing level of production bias, so any $b>0$ means bias has been traded for income, $I(b)$. Assume that $I(b)$ is concave and decreasing in $b$. Moving away from the net-income-maximizing manner of production is costly, but may have value to the manager if his incentives are not solely determined by net revenues. The value placed on additional control over the manner in which the service is provided is parameterized by $\rho$.

Production bias, $b$, should be also interpreted broadly to allow the maximization to reflect a diversity of missions beyond profit maximization. It represents some aspect of production (either input or output) about which the manager has preferences over and above this aspect's impact on net revenues. The $\rho$ term captures both the manager's own intrinsic value, the value he is induced to place on bias as a result of the historical orientation of the organization, and the influence of other interest groups, such as elite workers, governing boards, or those in a position of political power over the manager. ${ }^{4}$ The manager could enjoy biasing production out of an altruistic impulse, whereby the manager actually gets psychic benefit from providing excellent quality care or care to particular groups (such as the poor), over-and-above the net revenue consequences. A governing board or tax authority may encourage the manager

\footnotetext{
${ }^{3}$ An alternative interpretation for the decreasing marginal value of qualifying spending comes from recognizing that the costs of disguising non-qualifying spending as qualifying increases in the amount of spending so disguised.

${ }^{4} \mathrm{~A}$ more detailed version of this model could include interest group effort to exert influence over the manager with some cost to the interest group. This model would be similar to Glaeser (2003). In the model above we do not assume differential pressure or effort on the part of workers in nonprofit versus for-profit firms. If we did include this elite worker effort, nonprofit elite workers would have a greater incentive to exert effort because of the diminishing marginal returns to income in the nonprofit firm would make the nonprofit manager more responsive to influence. The direction of the behavioral differences between nonprofit and for-profit managers would remain the same, but the differences would be larger. We present only the basic case above, and let the empirical section reveal the size of the differences.
} 
to bias production towards the firm's mission. Finally, the manager could be captured or influenced to place extra weight on the impact of this service on some organized group, perhaps elite workers. Services with substantial elite worker production might have greater potential for quality improvement, for example, and the workers, or the manager himself, may benefit from being associated with a high-quality medical institution. In the hospital context, physicians are highly trained specialists with significant informational advantages and decision influence. The manager might alter the service provision by changing $b$ in services with a large percentage of elite workers. These workers could prefer a production mix that differs from income-maximizing levels, and pressure the manager to alter the provision of services they dominate. This high-quality service could produce better patient outcomes (influencing revenues) but be costly to implement (influencing costs). The revenue and cost effects of this high-quality service appear in $I(b)$, but the private benefits appear in the $\rho b$ term. As a second example, political pressures to over-employ labor could induce the manager to bias service provision. In that case, the manager might alter the mix of inputs away from the net-revenue-maximizing mix in favor of labor inputs. It is important to note, in all these cases, that production bias can be either good or bad from an overall efficiency standpoint, depending on the other characteristics of the market. Deviation from profitmaximizing choices may not reduce social welfare if quality is difficult to observe, as is often the case in health care markets with asymmetric information.

In-House Production Figure 1 represents the equilibrium choice over income versus production bias before outsourcing is introduced, holding $\rho$ fixed. Bias $(b)$ appears on the x-axis and net income $I$ on the y-axis. Let $j=f p$ denote for-profit and $j=n p$ denote nonprofit. The solid thick curve is the in-house production possibilities curve over combinations of income and bias choices, labeled $I(b)$. The optimal choice for each firm is where the manager's indifference curve is tangent to the in-house production possibilities curve. Beginning at the lower right, with low income and high bias, for-profit and nonprofit indifference curves are the same, with slope above $-\rho$. However, as we move towards the upper left, bias is traded off for income. Because nonprofit net revenues can only be used for qualifying spending, $q$, the value of additional income falls off more quickly for the nonprofit. Note this in the gray "nonprofit IC" line, which begins curving away from the black "for-profit IC" as more bias is traded off for income. The optimal choices for the two ownership types are shown by the dots on the in-house production possibilities curve, with biases $b^{j}$ and incomes $I^{j} \equiv I\left(b^{j}\right)-F$. Tangency assures that the bias level chosen by the for-profit will be lower than the nonprofit, or $b^{f p} \leq b^{n p}$. Intuitively, since the marginal value of a constrained dollar is always weakly less than the marginal value of an unconstrained dollar, and reducing bias delivers 
Figure 1: Optimal In-House Production by Firm Type

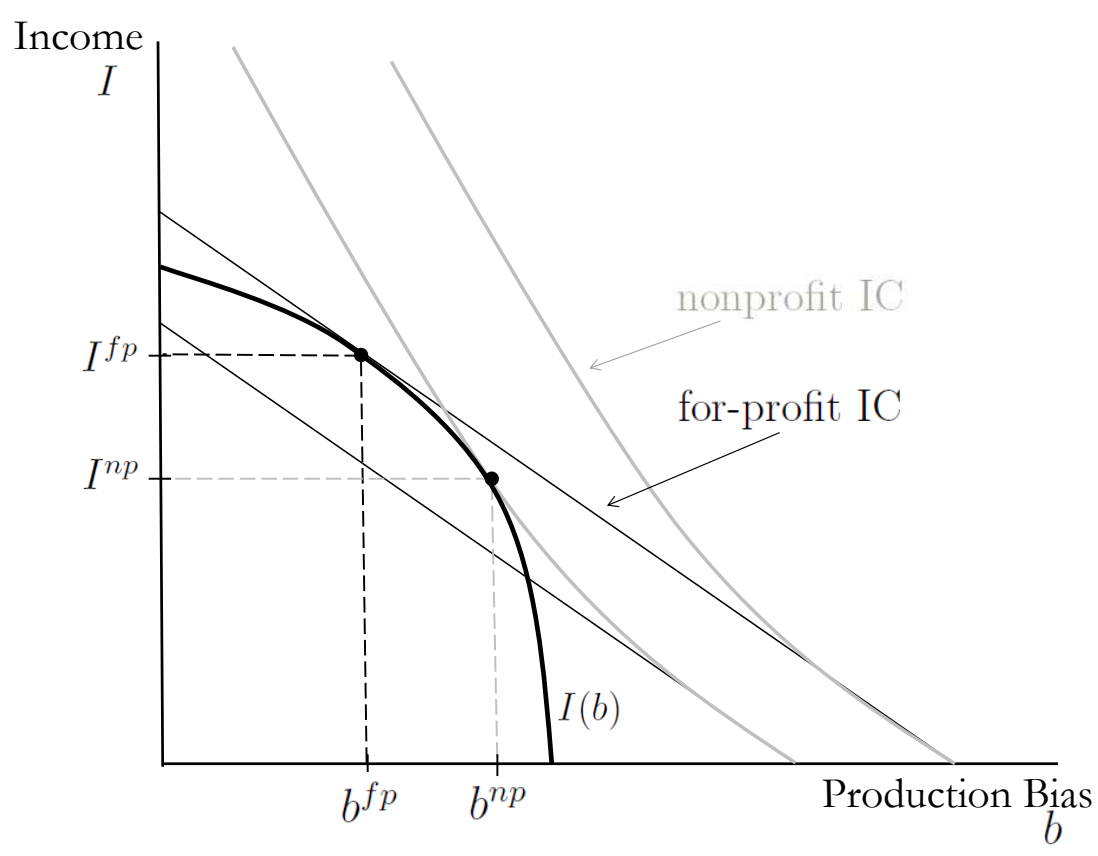

constrained dollars to non-profits and unconstrained dollars to for-profits, nonprofits choose weakly higher levels of production bias than for-profits do.

Outsourcing Assume now that the firm could choose to outsource production to some third party, who offers a different income for a given level of bias. Let $\bar{I}_{j}(b)$ be the threshold income for a given bias, $b$, where for an offered income above that threshold a type-j firm would choose to outsource instead of producing in-house. The points $\bar{I}_{j}(b)$ are exactly the maximal indifference curve attainable in-house. Figure 2 illustrates these thresholds for one fixed level of production bias, $b_{o}$, the dotted vertical line. For a given level of bias $b_{o}$, the cutoff income $\bar{I}_{n p}\left(b_{o}\right)$ begins where $b_{o}$ intersects the nonprofit indifference curve, as indicated by the small circle. The for-profit threshold income, $\bar{I}_{f p}\left(b_{o}\right)$, falls below, at the circled intersection of the for-profit indifference curve and $b_{o}$. For this particular level of bias, $b_{o}$, the for-profit finds outsourcing at this level of bias (weakly) more attractive than the nonprofit. Alternatively stated, once it begins consuming non-qualifying benefits, the for-profit firm requires lower income to choose outsourcing over own-production, or $\bar{I}_{n p}\left(b_{o}\right) \geq \bar{I}_{f p}\left(b_{o}\right)$, as shown on the y-axis.

Because the marginal rate of substitution between bias and income for the for-profit firm is weakly smaller (in absolute size) than that of the similarly-situated nonprofit firm, these 
Figure 2: Outsourcing Income Threshold by Firm Type

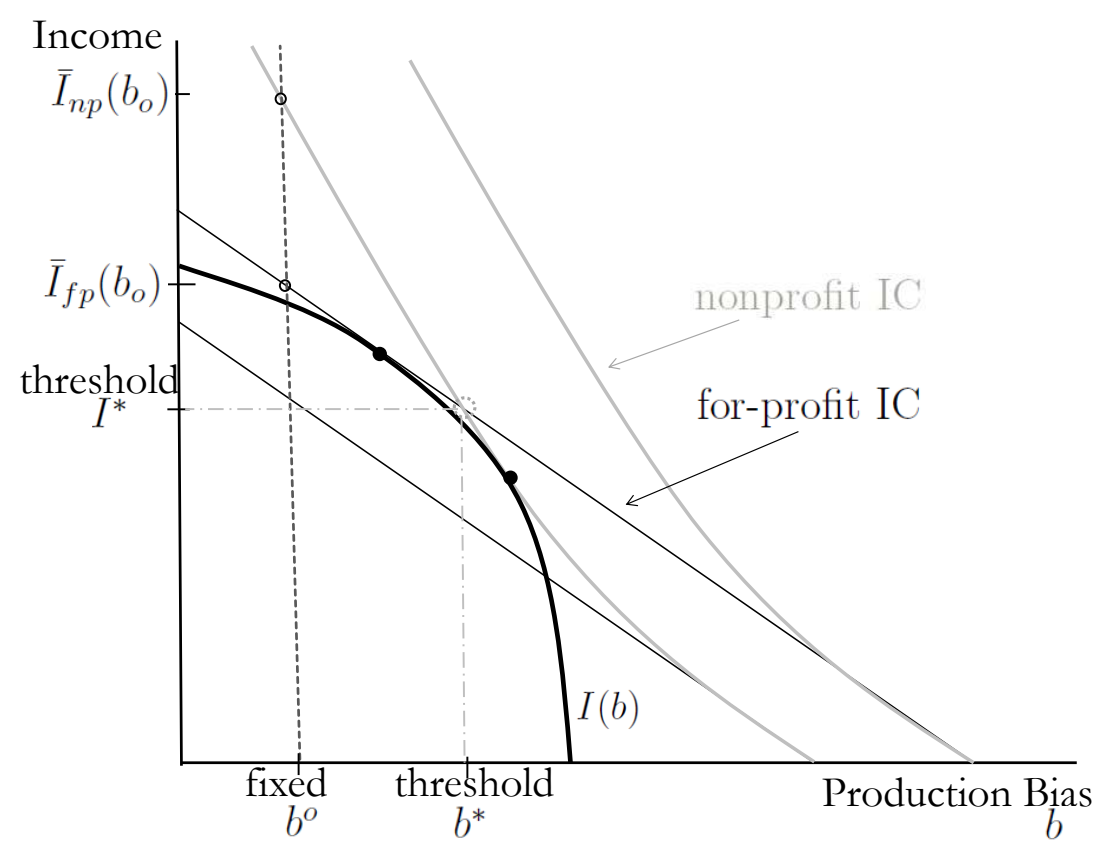

two indifference curves cross exactly once and the crossing occurs between their optimal in-house bundles. This fact is illustrated in Figure 2 where the intersection is contained in a gray dotted circle, labeled on the corresponding axes as $\left(b^{*}, I^{*}\right)$. The following proposition formalizes this intuition. Proofs for all propositions are in the Appendix.

Proposition 1 If $b^{f p} \neq b^{n p}$, then there is a unique combination $\left(b^{*}, I^{*}\right)$ such that $u\left(0, I^{*}, b^{*}\right)=$ $u\left(I^{*}-\bar{q}, \bar{q}, b^{*}\right)$. This combination is bracketed by the two in-house choices, in the sense that $b^{f p}<b^{*}<b^{n p}$ and $I^{f p}>I^{*}>I^{n p}$. Furthermore,

1. If $b \geq b^{*}$ then $\bar{I}_{n p}(b) \leq \bar{I}_{f p}(b)$.

2. If $b \leq b^{*}$ then $\bar{I}_{n p}(b) \geq \bar{I}_{f p}(b)$.

Finally, let $I^{o}(b)$ represent the frontier of income-bias pairs available through outsourcing. A firm of type $j$ will outsource if and only if there is some bias level such that $I^{o}(b)>\bar{I}_{j}(b)$.

From this proposition, we can characterize when to expect for-profit firms to outsource more than nonprofits and vice-versa. Intuitively, if outsourcing is the low-cost but low-bias option, we should see for-profit firms outsourcing at a higher rate than nonprofit firms. If outsourcing is the high-cost and high-bias option, we should see nonprofit firms outsourcing 
Figure 3: Outsourcing Opportunity Set Where For-Profit Firm Outsources but Nonprofit Firm Does Not

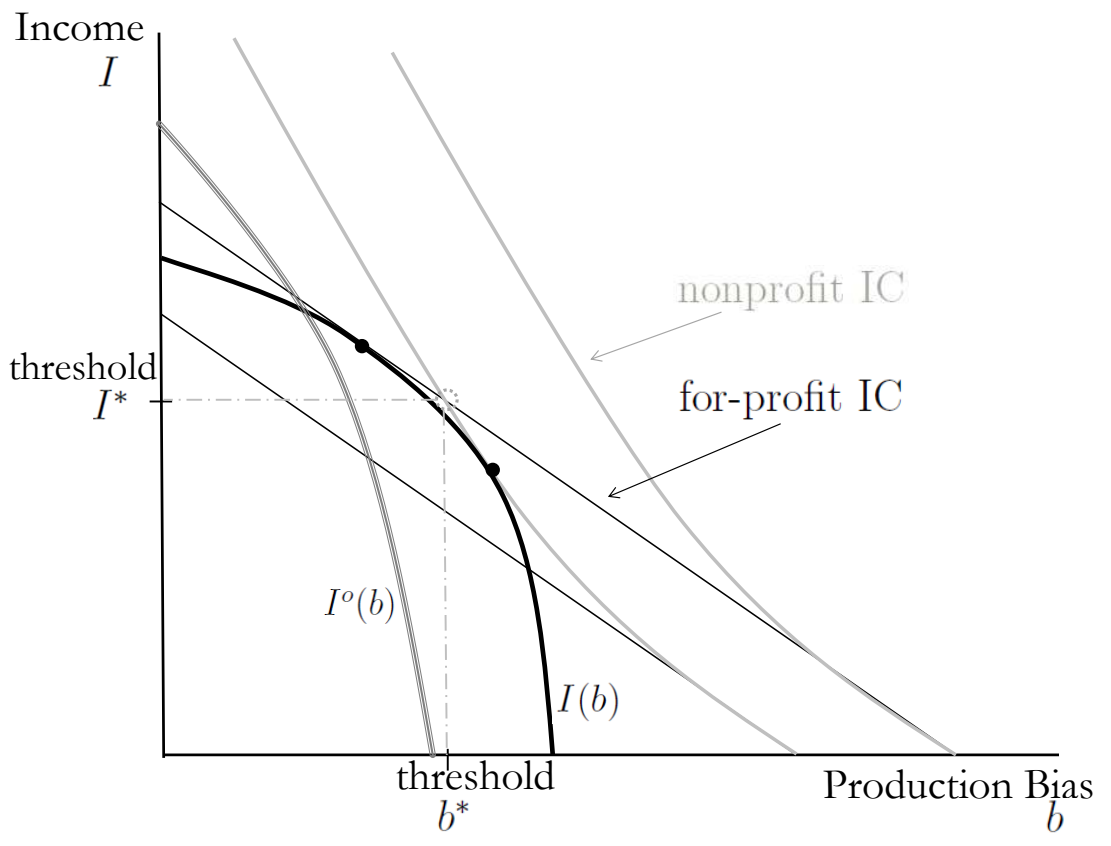

at a higher rate. Obviously, if outsourcing is lower cost for all bias levels, everyone will outsource, and if it is higher cost for all bias levels, no one will.

The following corollary formalizes these ideas.

Corollary 1 If $I^{o}(b)>I(b)$ only if $b<b^{*}$, then a nonprofit firm will outsource only if an otherwise identical for-profit firm does. If $I^{o}(b)>I(b)$ only if $b>b^{*}$, then a for-profit firm will outsource only if an otherwise identical nonprofit firm does.

Figure 3 represents a situation from Corollary 1 in which the outsourcing opportunity is relatively cheap for low levels of bias, but producing in-house is relatively cheap for high levels of bias. The thick multi-stripe frontier labeled $I^{o}(b)$ represents the new possibilities of outsourcing opportunities. The thick line $I(b)$ remains the in-house production possibilities. The outsourcing frontier lies above in-house production only for low levels of bias. Given this arrangement of production possibilities curves, a for-profit will choose to outsource, since the outsourcing frontier lies above the for-profit firm's maximal in-house indifference curve, while a nonprofit firm will not, as the outsourcing frontier is always below the nonprofit firm's maximal in-house indifference curve.

The propositions and figures above show how outsourcing behavior differs for fixed parameters. However, we can also investigate the comparative static predictions by firm type. 
The model predicts that a shock to fixed costs ( $F$ increasing) will differentially affect the two firm types. A fixed-cost shock is a shift in net income for all levels of bias. For profitmaximizing firms consuming some non-qualifying spending, changes in fixed costs have no effect on behavior (assuming they have sufficient profits to continue to consume non-qualified spending). By contrast, fixed costs immediately affect the nonprofits' income-bias tradeoff. If $F$ rises, the marginal benefit of qualified spending rises, so the opportunity to outsource to a low-cost/low-bias producer becomes more attractive to a nonprofit firm. This comparative static arises naturally from the non-distribution constraint, but it would not obtain in a model where the only difference between nonprofits and for-profits is a difference in $\rho$, the importance of control over production bias. In that alternative model, a fixed shock does not affect the marginal value of a dollar of additional net revenues and so would not affect outsourcing decisions (other than through shut-down constraints). An important contribution of this paper is our ability to show this distinction through an exogeneous fixed cost shock to firms.

A second comparative static is the response to a change in the importance of control over production $(\rho)$. If control over production is more important, a larger income advantage is required to induce firms to outsource to a low-bias producer. Since nonprofits must consume this income through qualifying spending, the effect is more pronounced for them. Of course, this static also implies that if nonprofits have consistently higher $\rho$ s for (some subset of) services, they will outsource (that subset of) services less, ceteris-paribus. We are able to test this in our application to hospitals, since these are necessarily multi-product firms with a variety of services with different expected bias levels.

Finally, since the divergence of the nonprofit from the profit-maximizing choice is larger for larger $\rho$, there is a cross-partial prediction, where the effects of a fixed-cost shock will be larger for services where control over production is more important. The following proposition formalizes these three comparative statics.

Proposition 2 If $b<b^{*}$, then $\bar{I}_{N P}(b)-\bar{I}_{F P}(b)$ is positive, increases in $\rho$, decreases in $F$, and the marginal effect of increasing $F$ is larger (in absolute value) as $\rho$ increases.

These propositions have implications for both the level of outsourcing in similarly-situated nonprofit and for-profit firms as well as for the mix of services they outsource. We can illustrate these predictions with a few common hospital services. Overall, we will see empirically that nonprofits generally outsource less than for-profits in all services, as shown in Proposition 1. A second effect also arises: as the value of production bias increases, we should see greater divergence between the outsourcing decisions of the nonprofit and the for-profit. 
Table 1 illustrates, with a few common hospital services, the four cases that arise from differences in the cost savings of outsourcing versus the value of biasing production. Consider a low-cost, low-bias-value service such as Groundskeeping. Many contractors likely exist outside of the hospital and the contract is not difficult to write. Quality is relatively easy to monitor. In addition, Groundskeeping is not a service that is likely to be key to the hospital's mission or important to elite workers. Table 1 shows that nearly all hospitals outsource this service, with for-profits outsourcing about 95 percent of groundskeeping on average, and nonprofits outsourcing nearly 88 percent on average. Another service not central to the mission or subject to the influence of elite workers is Plant Maintenance. In contrast to Groundskeeping, Plant Maintenance likely involves a more complicated contract and specialized services, reducing cost savings, but still not likely to be high bias. As such, we expect that hospitals of all types outsource this service less, but the rates should not differ much between ownership types. In fact, for-profits outsource about 34 percent, on average, of their Plant Maintenance services while nonprofits outsource about 5 percentage points less. In the next two services, bias may be more important. Public Relations firms are common in most markets, and thus may be relatively cheap to outsource. However nonprofits may wish to have greater control over interactions with their community. We observe that nonprofits outsource this service over 18 percentage points less than for-profits, at about 32 percent on average. The average for-profit outsources over half of its Public Relations services. Finally, for services that are both high cost and have a high value of biasing production, we should see both ownership types largely keeping production in-house because of complicated contracting, but for-profits will outsource slightly more. Anesthesiology is a good example of a service where quality is important and also where elite workers play a key role. In this service, outsourcing is rare for both ownership types. However, nonprofits outsource barely more than 5 percent on average in Anesthesiology, whereas the average for-profit outsources at a higher level of over 15 percent..$^{5}$

In keeping with these examples, there are several reasons to focus on outsourcing as the low-cost, low-bias-value option, that is $I^{o}(b)>I(b)$ for low $b$. In addition to the direct contractual obligations, $I^{o}(b)$ also includes all the costs of composing and managing a (potentially quite complex) contractual relationship. Duties and contingencies have to be clearly specified and appropriately anticipated. Unanticipated contingencies may result in costly renegotiations. Performance must be monitored, and a breach on either side can lead to costly and protracted legal proceedings (Bajari and Tadelis 2001, Levin and Tadelis 2010). More finely tuned control over the manner of production requires even more completely

\footnotetext{
${ }^{5}$ Service-specific full regressions of these four services showing the above effects in detail can be provided upon request.
} 
Table 1: Illustration of The Effect of the Cost of Contracting and The Value of Bias on Predicted and Actual Outsourcing Rates

\begin{tabular}{lllllccc}
\hline \hline Value of & Cost of & \multicolumn{2}{c}{ Predictions } & & \multicolumn{3}{c}{ Avg Pct Outsourced } \\
Bias & Contracting & Level & $\Delta$ & Service & FP & NFP & $\Delta$ \\
\hline Low & Low & High & Small & Groundskeeping & 94.8 & 87.9 & 6.9 \\
Low & High & Low & Small & Plant Maintenance & 34.2 & 29.4 & 4.8 \\
High & Low & High & Big & Public Relations & 51.1 & 32.4 & 18.7 \\
High & High & Low & Big & Anesthesiology & 15.7 & 5.2 & 10.5 \\
\hline \hline
\end{tabular}

specified contracts and precise monitoring. Providing high quality service, for example, is notoriously difficult to measure in a contractible way, and a contractor has strong incentives to try to shade on quality to the extent that it lowers his costs. Similarly, a contractor has strong incentives to try to game a contract that requires a "biased" production mix (say favoring labor over capital), since returning to the optimal mix would reduce costs. In both cases, the desire to game the contract increases when a contract specifies greater divergence from the profit-maximizing production method. At some point, the costs of contractually guaranteeing very high levels of control over specific details of production would be prohibitive relative to in-house monitoring.

The cost of controlling production may also increase with outsourcing in this industry, in particular, because of the structure of health care services. Hospitals are organized to provide tertiary care, the most specialized consultative care for patients. Patients are referred to hospitals from primary or secondary care, which are organized to provide more general care. Thus, hospitals' patients may already require the most specialized services in the local market, so a full specification of appropriate performance is particularly difficult. In a sense, the hospital gets the least standard cases, by design, and so a standardized contractual solution may be particularly ineffectual. Of course, this pattern of comparative advantage may not hold for every service, but it suffices, for our purposes, for it to hold on average.

\subsection{Empirical Predictions}

The theoretical model gives us four predictions to test regarding outsourcing behavior and ownership type. They are:

1. Nonprofit hospitals should outsource less overall, across all services. (Corollary 1)

2. Differences in outsourcing between nonprofits and for-profits should be more pro- 
nounced for services where bias is important. (Proposition 2)

3. Differences in overall outsourcing between nonprofits and for-profits should decrease as budgets tighten. (Proposition 2)

4. As budgets tighten, outsourcing differences should change the most in services where bias is important. (Proposition 2)

We will examine the evidence for and against these propositions below.

\section{$3 \quad$ Data and Institutional Setting}

We examine the implications of the model using data on California hospitals, 1996-2008. The data is an unbalanced panel of 433 short-term care general hospitals from the Annual Financial Data series from the California Office of Statewide Health Planning and Development (OSHPD). For each hospital, we know a wide variety of ownership, financial, and operating characteristics, including ownership type, discharges, patient mix, and location.

California hospitals are of four ownership types: for-profit, nonprofit, local, and district. ${ }^{6}$ For-profit hospitals have a private residual claimant on profits, Nonprofits are 501(c)(3) registered charitable organizations, and no part of the organization's net earnings accrue to the benefit of any private shareholder or individual. ${ }^{7}$ These first two categories are private organizations, in contrast to the last two, which are publicly-run. Local hospitals are operated as part of the budget of the local city or county, and overseen by a board appointed by the elected local government. District hospitals are controlled by a directly-elected board for each of California's 85 health districts. These hospitals are funded by taxes at the district level, patient receipts, and intergovernmental transfers. ${ }^{8}$

\subsection{Measuring Outsourcing}

The Annual Financial data includes a measure of total operating expenses for every service provided by the hospital, from medical services to administrative tasks. However, the

\footnotetext{
${ }^{6}$ Veterans Affairs (VA) hospitals are not included in this analysis.

${ }^{7}$ Separating out church-affiliated hospitals from non-affiliated nonprofits reveals a similar pattern for both groups, although church-affiliated nonprofits have lower overall outsourcing levels.

${ }^{8}$ In fact, the situation is slightly more nuanced, because certain Districts license nonprofit or for-profit providers to operate hospitals for them. We code these as for-profit or nonprofit, since the licensees are residual claimants on profits and have managerial discretion in structuring operations. For more detail about the governance structures employed by California public hospitals, see http://www.chcf.org/publications/ 2009/05/governance-models-among-california-public-hospitals
} 
OSHPD makes all hospitals also report operating expenses net of any physician expenses, either from direct employment or through outsourcing. This is because most California hospitals are legally prohibited from directly employing physicians. This facilitates crosshospital comparisons with the select few exceptions to this prohibition. ${ }^{9}$ This separation is helpful in our case, since the make-or-buy "decision" in physician employment is not a choice, but instead dictated by law. We can thus isolate the costs where a meaningful outsourcing decision is taking place. Reported total operating expenses are divided into two categories: Total Direct Costs and Physicians' Professional Component. Total direct costs are the operating expenses net of physician costs. We use total direct costs in our analysis in order to exclude physician fees and include only the remaining components of operations which are salient to the make-or-buy decision. ${ }^{10}$

Now that we have a measure of a hospital's total expenses which are subject to outsourcing decisions, total direct cost, we examine what component of these costs come from outsourced sources. Within each service, the hospital reports the total costs divided into broad component categories such as Salaries and Wages, Benefits, or Supplies. Costs attributed to outsourced sources are recorded in two categories. The first, Professional Fees, is essentially all outsourced labor costs. Professional Fees include (non-physician) medical personnel not on the payroll, such as registered nurses or physical therapists. It also includes legal or management consulting fees, audit personnel, or temporary contractors such as file clerks. The second category of outsourced costs is Purchased Services. This category includes the costs of outsourced medical services such as a contracted laboratory or CT scan. It can also include services such as repairs and maintenance, management services, linen services, or credit and collection that were provided by an outside contractor.

We define a cost-based measure of service-specific outsourcing using the sum of the two outsourced cost categories as a percentage of Total Direct Costs in that service. Formally, for service $s$ in hospital $h$ in year $t$ we define:

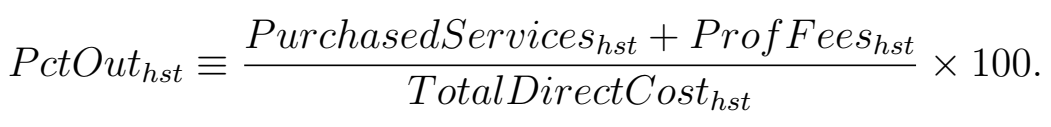

Our measure of outsourcing is the percent of the total direct costs that were outsourced in that service for a given hospital-year observation. Hospitals differ most in the extent of

\footnotetext{
${ }^{9} \mathrm{~A}$ few exceptions to directly employing physicians include county hospitals, HMOs licensed under the Knox-Keene Act (such as Kaiser), and teaching hospitals. See "Physician-Hospital Integration 2012: How Health Care Reform is reshaping California's Delivery System." for The California HealthCare Foundation by the Camden Group. April 2012.

${ }^{10}$ Total direct costs also excludes the reporting category of "Unassigned Costs," which is expenses such as Insurance, Depreciation, or Interest, since these costs cannot be outsourced.
} 
outsourcing of a given service, rather than the decision to outsource at all. Because of this, we will defer the extensive margin to another paper, and focus here on the intensive margin of the degree of outsourcing, which we will measure as $\log \left(\right.$ PctOut $\left._{h s t}\right)$.

\subsection{Services}

Hospitals in our sample offer a subset of 85 unique services. Table 2 lists the six major categories of services with examples and the average outsourcing levels across all hospitals. We see broad trends arise already in Table 2 across service types. The category with the least amount of outsourcing overall is Daily Hospital Services, with mean outsourcing levels of 7.1 percent and a standard deviation of approximately 11 percent. Daily Hospital Services includes inpatient care such as surgeries and coronary care. Fiscal Services have the highest rates of outsourcing at 28.5 percent on average, with services such as general accounting and credit and collection. General Services also has high levels of outsourcing, on average 24 percent, for services such as laundry and linens and groundskeeping. The median hospital offers 56 unique services, while the mean hospital offers $53.7 .^{11}$

Table 2: Service Categories Description

\begin{tabular}{llrc}
\hline \hline Service Category & Examples & $\begin{array}{c}\text { Mean Pct } \\
\text { Outsourced }\end{array}$ & $\begin{array}{c}\text { Std. } \\
\text { Dev. }\end{array}$ \\
\hline Daily Hospital Services & Medical/Surgical Intensive Care, Coronary Care & 7.1 & 11.0 \\
Ambulatory Services & Medical Transportation, Home Health Services & 11.2 & 18.9 \\
Ancillary Services & Anesthesiology, Medical Equipment & 21.2 & 32.8 \\
General Services & Laundry and Linens, Groundskeeping & 24.2 & 33.5 \\
Fiscal Services & General Accounting, Credit and Collection & 28.5 & 35.5 \\
Administrative Services & Hospital Administration, Public Relations & 19.9 & 26.5 \\
\hline \hline
\end{tabular}

\subsection{Services and Bias}

Our model of outsourcing behavior implies bigger differences among ownership types when control over the services is particularly important to the manager. Proposition 2 shows

\footnotetext{
${ }^{11}$ These main 85 unique services exclude three categories. 1. Several broad catch-all categories. (such as "Other Daily Hospital Services", the composition of which may vary across hospitals) 2. Services offered very rarely (less than 300 hospital/year combinations, out of about 4500) 3. All medical research and education services. The results are robust to including/excluding the rare services, and we explicitly report the results when we limit the sample even further to only very common services.
} 
the difference between nonprofit and for-profit outsourcing behavior should increase in the importance of production bias.

The literature on nonprofit hospital behavior focuses on physicians, in particular, as likely candidates for elite workers with influence on the manager. Glaeser (2003) states, "the modern hospital is an outcome of the increasing power of doctors, who shaped the hospital toward their own interests." At the extreme, Pauly and Redisch (1973) model the hospital directly as a physicians' cooperative. We need not go that far, however, and merely require that physicians have some substantial influence on the induced preferences of the manager, especially in domains where they have informational advantages and strong incentives to influence decisions. To identify services where these elite workers are more prevalent, we categorize a subset of services which are "physician-intensive." As described in Section 3.1, each service's physician costs are reported separately from total direct costs because of the prohibition on direct employment. However, we can use these costs to create an index of services which rely heavily on physician inputs. We rank each service by the average fraction of total direct costs attributable to physician services. Those services in the top quintile of all services are designated as "physician-intensive services." 12 These services have the highest percentage of physician costs as a percent of their total costs among all the 85 hospital services. $^{13}$

Outside of private nonprofits and for-profits, public hospitals may have a different preference for bias. Services that are particularly labor-intensive could be salient to political overseers and regulators, either by satisfying their mission or through furthering political support. Local hospitals are run within the city or county government, and political principals may have a desire to disguise redistribution as public employment (Alesina, Baqir and Easterly 2000),(Clark and Milcent 2011). Other mechanisms for bias may be "Keynesian" employment policy or even capture by organized labor. We identify labor-intensive services using a similar method to that described for physician-intensive services. For each service in each hospital-year, we calculate the fraction of direct costs represented by the categories

\footnotetext{
${ }^{12}$ We used an alternative proxy in a prior version of this paper, where we followed the OSHPD division of services into revenue-generating and non-revenue-generating subsets. Revenue-generating services are those for which the hospital bills insurance and patients, thus these services are generally medical services, where physicians may have a greater impact on management policy. Non-revenue generating services are services which the hospital must provide for its operations, like groundskeeping, parking, and accounting, but for which the hospital does not generally charge. The results are quite similar for this proxy of physicianintensity. These results broadly square with some results broadly contrasting clinical and non-clinical costs at the hospital level (Balakrishnan et al. 2010).

${ }^{13}$ Physician-intensive services are pediatric intensive care, neonatal intensive care, adult psychiatric acute care, physical rehabilitation care, emergency services, clinic services, satellite clinic services, psychiatric partial hospitalization, anesthesiology, pathological lab services, cardiology services, electromyography, electroencephalography, pulmonary function services, psychiatric therapy, and medical staff administration.
} 
of Salaries and Wages and Employee Benefits. However, since some outsourcing may also reflect labor costs, which would not be reported in direct salaries because it was outsourced, this measure is a minimum estimate for the true share of labor in that service. We construct two additional measures of labor intensity: the share of non-outsourced direct costs and the share of total direct expenses of wages, benefits and contracts with outside providers. The latter of these is an upper bound on the true labor intensity, while the former will lie between the other measures. We define a service as "labor-intensive" if it is among the top third of services for all three metrics. ${ }^{14} 15$

\subsection{Hospital Characteristics}

For hospital covariates we have measures of size, scope, mission, and market. The number of discharges is a time-varying measure of size. For scope, we have the number of services offered. Since residency programs may lend an extra incentive to produce in-house for training purposes, we include an indicator for this aspect of mission. We also include the fraction of patient-days that are from Medicare and MediCal patients, since different patient mixes may lead to different activities. We also have an indicator for whether the state of California considers the hospital to be "rural," since the opportunities to outsource may be less in a less-developed market. ${ }^{16}$ To control for market characteristics, we match Census and American Community Survey data for 1996-2006 onto the Hospital Service Areas (HSAs) of each hospital. HSAs capture local health care markets for hospital care as a collection of zipcodes whose residents receive most of their hospitalizations from hospitals in that area. Market characteristics include population, socioeconomic characteristics, and demographics. Socioeconomic and demographic characteristics include median household income, educational attainment, and race percentages within the total population. The average unemployment rate for the year in the hospital's county is from the Bureau of Labor Statistics. County fixed-effects control for the general market in which the hospitals find themselves, and we

\footnotetext{
${ }^{14}$ If all labor-intensity metrics were the same, this procedure would identify 28 services, but since the ranking differs to some degree among the metrics, only 14 services meet all three criteria. Expanding the definition to include all services that meet two of the three criteria does not substantially alter our results.

${ }^{15}$ Labor-Intensive Services are medical/surgical intensive care, coronary care, definitive observation, acute care, psychiatric acute-adult, alternate birthing center, physical rehabilitation, sub-acute care, skilled nursing care, observation care, social work services, outpatient registration, nursing float personnel, and utilization management.

${ }^{16}$ A subset of about 20 of California's hospitals qualify for the Medicare "Critical Access Hospital" program for rural hospitals. These hospitals may face different incentives to provide services, and to provide them in-house. We have included them in the sample, but we repeated the entire analysis removing these hospitals, with no substantive effects on the results. For details on this program, see http://www.cms.gov/Outreach-and-Education/Medicare-Learning-Network-MLN/ MLNProducts/downloads/CritAccessHospfctsht.pdf.
} 
also include year and service fixed-effects to remove common economic shocks and maintain comparisons to within a service.

Finally, to control for service-specific returns to scale, we have service-specific measures of output. The specific measure reported by the OSHPD varies considerably by service. For example, the measure of output for all daily hospital services is "patient-days," and for most ambulatory services it is "visits," but for ancillary services it is very service-specific: deliveries, operating minutes, tests, or sessions. For the non-medical services, printing and duplicating services is measured in "reams of paper," while that for social work services is "number of personal contacts." 17 Since these measures are not commensurable, we will also allow the coefficient on output in any regression that includes them to vary by service, with the levels given in logs.

\subsection{Summary Statistics and Preliminary Differences}

Table 3 summarizes overall outsourcing, hospital characteristics, and market characteristics by hospital ownership type. ${ }^{18}$ In the summary statistics, all hospital-level variables are weighted by the number of services, since regressions are naturally weighted in that way.

Recall the first prediction of our model is that nonprofit hospitals should outsource less overall than for-profit hospitals. Preliminary differences in overall outsourcing behavior are evident in Table 3. For-profit hospitals outsource on average 25.7 percent of costs, compared to only 19 percent for private nonprofit hospitals. Public hospitals, district and local, also outsource less on average than for-profit hospitals. The fraction of services which are completely outsourced varies in a similar way. The ownership types are much more similar along the extensive margin, however, averaging about 87 percent of services outsourced to some degree.

The remaining variables in Table 3 give a picture of each hospital ownership type. Private for-profits are mostly small urban hospitals, averaging 6,146 discharges per facility and with only 5 percent of hospitals located in rural areas. Accordingly, for-profit hospital markets have the highest HSA populations, the highest median household income, and the second highest percent black. For-profits also offer a high percentage of "common" services, defined as a service offered by at least 3,000 hospital-years in the sample.

Nonprofit hospitals tend to be large medical complexes in relatively well-off areas. Non-

\footnotetext{
${ }^{17}$ A complete list of services and output measures available at http: //www . oshpd.ca.gov/HID/Products/ Hospitals/AnnFinanData/Manuals/index.html.

${ }^{18}$ We present results for all 85 services, but in the Appendix we replicate our results by limiting the analysis to the 36 most common services, which are offered by at least 3000 hospital/year combinations. They are consistent with the full-sample results.
} 
profit hospitals average 11,145 discharges, second only to local hospitals, and 58 services. They also have the smallest percentage of MediCal patients, at 20 percent, and the highest percentage of Medicare patients, at 45 percent. Only 76 percent of the services offered by nonprofit hospitals are "common" services. This is the lowest percentage among the ownership types, indicating that nonprofit hospitals are offering the broadest scope of services.

District hospitals are small, traditionally rural hospitals. They have the smallest number of average discharges, 5,770, and offer the lowest number of services, 52. District hospitals are the second largest provider for MediCal patients, behind local hospitals. Over 57 percent of district hospitals are classified as rural, almost five times the rate of the other ownership types. Accordingly, district hospitals have the lowest average population in the HSA, the lowest median income, and the lowest percent black.

Local hospitals are commonly very large teaching hospitals. These hospitals have the largest average number of discharges, at 12,751. These hospitals serve the greatest percentage of MediCal patients, at over 52 percent, and the least number of Medicare patients. The mix of services offered is slightly less diverse than nonprofits but broader than the other two ownership types. Local hospitals are by far the most likely to offer a residency program, with 74 percent of the local hospital observations doing so.

In the next section, we detail our econometric approach to address outsourcing differences while accounting for these differences in observables.

\section{Econometric Specification and Results}

\subsection{Econometric Specification}

Conditional on the decision to outsource the service to any degree, we model the underlying preference for outsourcing intensity as

$$
\log \left(\text { PctOut }_{h s t}\right)=\sum_{j} \beta_{j} O w n_{h t}^{j}+\gamma_{1 s}+\gamma_{2 s} \text { Output }_{h s t}+\Gamma X_{h t}+\epsilon_{h s t},
$$

where the dependent variable is the natural log of the percent of costs due to outside contracts, $O w n_{h t}^{j}$ is a dummy taking a value of 1 if hospital $h$ is of ownership type $j$ in year $t$, the $\gamma_{\mathrm{s}}$ are service-specific intercepts and output slopes, and $X_{h t}$ is the set of controls described in section 3.4, as well as county-specific and year-specific intercepts. The sample statistics suggest that the primary difference among ownership types comes from differences in the margin of intensity of outsourcing. 
Table 3: Summary Statistics by Ownership Type, Weighted by Number of Services.

\begin{tabular}{|c|c|c|c|c|}
\hline & For-Profit & Private NP & District & Local \\
\hline \multirow[t]{2}{*}{ Percent Outsourced } & 25.72 & 19.02 & 20.71 & 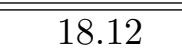 \\
\hline & $(33.93)$ & $(28.68)$ & $(30.55)$ & $(27.82)$ \\
\hline \multirow[t]{2}{*}{ Service Completely Out } & 0.0561 & 0.0294 & 0.0455 & 0.0232 \\
\hline & $(0.230)$ & $(0.169)$ & $(0.208)$ & $(0.150)$ \\
\hline \multirow[t]{2}{*}{ Service Any Out } & 0.863 & 0.865 & 0.867 & 0.876 \\
\hline & $(0.344)$ & $(0.342)$ & $(0.340)$ & $(0.330)$ \\
\hline \multirow[t]{2}{*}{ Discharges } & 6146.8 & 11145.4 & 5770.0 & 12750.5 \\
\hline & $(4518.5)$ & $(7677.4)$ & $(6560.5)$ & $(10530.7)$ \\
\hline \multirow[t]{2}{*}{ Services Offered } & 53.09 & 57.72 & 51.98 & 55.93 \\
\hline & $(8.637)$ & $(9.807)$ & $(10.39)$ & $(7.993)$ \\
\hline \multirow[t]{2}{*}{ Pct. MediCal } & 27.60 & 20.19 & 38.42 & 52.92 \\
\hline & $(21.34)$ & $(15.88)$ & $(25.62)$ & $(13.84)$ \\
\hline \multirow[t]{2}{*}{ Pct. Medicare } & 44.28 & 45.25 & 37.05 & 16.40 \\
\hline & $(16.98)$ & $(13.85)$ & $(19.43)$ & $(11.01)$ \\
\hline \multirow[t]{2}{*}{ Common Service } & 0.829 & 0.760 & 0.812 & 0.785 \\
\hline & $(0.377)$ & $(0.427)$ & $(0.391)$ & $(0.411)$ \\
\hline \multirow[t]{2}{*}{ Residency Program } & 0.164 & 0.249 & 0.0237 & 0.736 \\
\hline & $(0.370)$ & $(0.432)$ & $(0.152)$ & $(0.441)$ \\
\hline \multirow[t]{2}{*}{ Rural } & 0.0532 & 0.119 & 0.576 & 0.123 \\
\hline & $(0.224)$ & $(0.324)$ & $(0.494)$ & $(0.329)$ \\
\hline \multirow[t]{2}{*}{ Peak Acceleration } & 0.496 & 0.475 & 0.465 & 0.525 \\
\hline & $(0.141)$ & $(0.227)$ & $(0.256)$ & $(0.225)$ \\
\hline \multirow[t]{2}{*}{ Pop. in HSA } & 502004.0 & 342956.8 & 131289.8 & 429471.6 \\
\hline & $(640210.0)$ & $(428365.0)$ & $(170351.8)$ & $(497746.1)$ \\
\hline \multirow[t]{2}{*}{ Pct. Black in HSA } & 6.845 & 5.237 & 3.237 & 7.771 \\
\hline & $(7.921)$ & $(6.299)$ & $(4.234)$ & $(9.852)$ \\
\hline \multirow[t]{2}{*}{ Pct. Poor in HSA } & 14.39 & 13.19 & 14.68 & 14.92 \\
\hline & $(6.892)$ & $(6.067)$ & $(6.232)$ & $(6.393)$ \\
\hline \multirow[t]{2}{*}{ med. HH Earn in HSA } & 45884.2 & 45793.7 & 38025.6 & 42543.1 \\
\hline & $(15285.5)$ & $(14549.9)$ & $(11250.8)$ & $(13140.0)$ \\
\hline \multirow[t]{2}{*}{ HS Grad in HSA } & 21.25 & 21.69 & 25.07 & 21.93 \\
\hline & $(5.042)$ & $(5.791)$ & $(5.685)$ & $(5.410)$ \\
\hline \multirow[t]{2}{*}{ Some Col. in HSA } & 25.66 & 26.61 & 27.44 & 25.63 \\
\hline & $(8.450)$ & $(9.000)$ & $(9.402)$ & $(9.353)$ \\
\hline \multirow[t]{2}{*}{ Pct Bach. in HSA } & 15.99 & 16.76 & 12.29 & 14.44 \\
\hline & $(6.641)$ & $(7.443)$ & $(5.633)$ & $(7.337)$ \\
\hline \multirow[t]{2}{*}{ Pct Grad/Prof in HSA } & 7.962 & 8.607 & 5.798 & 7.302 \\
\hline & $(4.816)$ & $(6.031)$ & $(3.384)$ & $(4.344)$ \\
\hline \multirow[t]{2}{*}{ County Unemp. } & 5.873 & 6.295 & 7.882 & 7.450 \\
\hline & $(1.874)$ & $(2.335)$ & $(3.869)$ & $(4.099)$ \\
\hline $\mathrm{N}$ & $57 \mathrm{k}$ & $128 \mathrm{k}$ & $27 \mathrm{k}$ & $15 \mathrm{k}$ \\
\hline
\end{tabular}

Sample means and standard deviations in parentheses at the service $\mathrm{x}$ hospital $\mathrm{x}$ year level. 
We observe the choice of intensive margin only in the cases where the hospital decides to outsource at all, a selected sample of the population. Naively dropping those observations and ignoring the sample selection can lead to biased estimates, so we need to model the extensive margin, whether to outsource at all, even if our primary interest is in outsourcing intensity. Let $y_{s h t}$ represent the payoff to firm $h$ in year $t$ from outsourcing service $s$ at the profit-maximizing intensity level, relative to the zero-normalized payoff of producing that service entirely in house. The true payoff is unobservable, but our empirical model for this outsourcing payoff is

$$
y_{h s t}=\sum_{j} \beta_{j} O w n_{h t}^{j}+\gamma_{1 s}+\gamma_{2 s} \text { Output }{ }_{h s t}+\Gamma X_{h t}+\epsilon_{h s t},
$$

where the independent variables are identical to those in (2). Under joint normality, the bias of our intensity estimate can be corrected by jointly estimating equations (2) and (1) using a maximum likelihood estimator (Heckman 1979). In fact, as we will see below, the evidence is that this bias is not significant, and the naive estimates are extremely close to the corrected estimates.

Finally, there is a question of which covariates are appropriate to include as control variables. On one hand, we know that for-profit hospitals and the various types of nonprofits are dissimilarly situated, on average, in terms of economic environment, patient mix, and even scale and scope of operations. These differences are quite apparent in the sample means, and these factors may be correlated with the attractiveness of outsourcing for reasons unrelated to the ownership form of the hospital. Thus, we may want to control for these factors in order to contrast the various nonprofit forms to a hypothetical similarly-situated for-profit hospital. Failing to do so may result in biased estimates, since outsourcing differentials may result from these third factors that are correlated with ownership.

On the other hand, the dissimilar situations did not arrive by happenstance. Instead, they often result from hospitals of different ownership types making different business decisions. To take one example, consider the hospital's decision to operate in an urban market. We know that, on average, for-profit hospitals are more likely to operate in urban markets than, especially, their district hospital counterparts. If part of the reason they do this is because for-profit hospitals want to avail themselves of the thicker markets for outsourcing services in urban areas, then the decision to locate in an urban area is an intermediate outcome to the decision to outsource at higher rates. If this is the case, then urban location is an inappropriate control and including it will introduce bias. Put another way, if for-profit hospitals have some unmodelled reason to prefer locating in urban locations, then those for-profit hospitals that choose to operate in rural areas have some unusual (unobserved) 
characteristic. Thus, rural for-profits are not actually similarly situated to rural district hospitals, which do not need this unusual characteristic to choose a rural setting. This induced difference becomes a problem whenever that unobserved characteristic also influences the attractiveness of outsourcing.

We believe that the omitted variable problem induced by having too few controls is more severe than the intermediate-outcome problem, and we will, therefore, present regression estimates including the full set of controls outlined. We also perform our estimates for a smaller set of controls that are plausibly beyond the control of the firm, omitting the controls for patient mix, residency, number of beds, number of services, and service-specific output. These estimates are less likely to suffer from the intermediate-outcome problem and consistently result in larger differences. ${ }^{19}$ The sample means, of course, reflect the uncontrolled differences.

\subsection{Prediction 1: Differences in Overall Outsourcing Levels}

The first prediction of the model is that nonprofit hospitals should outsource less overall, across all services. Table 4 shows the results of the full estimation of the Heckman selection model and from a fixed-effects OLS estimate of outsourcing intensity. The coefficients report marginal effects, calculated at the mean of the covariates. The first thing to note is the similarity of the OLS and Heckman results. They are essentially indistinguishable, suggesting that the naive approach, where we limit our attention to services that are outsourced at all, is not leading to major biases. This result is not too surprising, given that about 87 percent of service-hospital-year observations are outsourced to some extent and we are already controlling for many of the factors that might guide that decision. Given the high level of similarity, for the rest of the analysis we will ignore selection and simply present OLS results for brevity.

The overall outsourcing results are generally in accord with the first prediction of the model about outsourcing differences. Table 4 reports the coefficients on each of the ownership types as compared to the omitted category of for-profits. Nonprofit hospitals outsource 8 percentage points less than similarly-situated for-profits. ${ }^{20}$ District hospitals are similar to private nonprofits, outsourcing about 13 percentage points less intensely than their for-profit counterparts. Local hospitals are the least intense outsourcers of all, outsourcing nearly 39

\footnotetext{
${ }^{19}$ Results available on request.

${ }^{20}$ It is possible that some subset of the nonprofits in our sample are simply "for-profits in disguise", by somehow evading the non-distribution constraint. Here, and throughout, the existence of such firms would attenuate our estimated differences, as compared to the actual difference between truly constrained nonprofits and their unconstrained for-profit counterparts.
} 
Table 4: Outsourcing and Ownership Type

\begin{tabular}{|c|c|c|}
\hline & $\begin{array}{c}(1) \\
\text { OLS } \\
\end{array}$ & $\begin{array}{c}(2) \\
\text { Heckman } \\
\end{array}$ \\
\hline Non-Profit & $\begin{array}{c}-0.079^{*} \\
(0.046)\end{array}$ & $\begin{array}{c}-0.079^{*} \\
(0.046)\end{array}$ \\
\hline District & $\begin{array}{c}-0.126^{*} \\
(0.067)\end{array}$ & $\begin{array}{c}-0.126^{*} \\
(0.067)\end{array}$ \\
\hline Local & $\begin{array}{c}-0.386^{* * *} \\
(0.089)\end{array}$ & $\begin{array}{c}-0.386^{* * *} \\
(0.089)\end{array}$ \\
\hline Log Discharges & $\begin{array}{c}-0.125^{* * *} \\
(0.027)\end{array}$ & $\begin{array}{c}-0.126^{* * *} \\
(0.027)\end{array}$ \\
\hline Log (Services) & $\begin{array}{l}-0.064 \\
(0.155)\end{array}$ & $\begin{array}{l}-0.054 \\
(0.153)\end{array}$ \\
\hline Rural & $\begin{array}{l}-0.016 \\
(0.069)\end{array}$ & $\begin{array}{l}-0.016 \\
(0.069)\end{array}$ \\
\hline Pct. MediCal & $\begin{array}{c}0.001 \\
(0.001)\end{array}$ & $\begin{array}{c}0.001 \\
(0.001)\end{array}$ \\
\hline Pct. Medicare & $\begin{array}{c}0.000 \\
(0.001)\end{array}$ & $\begin{array}{c}0.000 \\
(0.001)\end{array}$ \\
\hline Pop. in HSA & $\begin{array}{l}-0.000 \\
(0.000)\end{array}$ & $\begin{array}{l}-0.000 \\
(0.000)\end{array}$ \\
\hline Pct. Black in HSA & $\begin{array}{c}0.003 \\
(0.003)\end{array}$ & $\begin{array}{c}0.003 \\
(0.003)\end{array}$ \\
\hline County Unemp. & $\begin{array}{c}-0.006 \\
(0.009)\end{array}$ & $\begin{array}{l}-0.006 \\
(0.009)\end{array}$ \\
\hline Pct. Poor in HSA & $\begin{array}{l}-0.006 \\
(0.005)\end{array}$ & $\begin{array}{l}-0.006 \\
(0.005)\end{array}$ \\
\hline HS Grad in HSA & $\begin{array}{c}-0.003 \\
(0.004)\end{array}$ & $\begin{array}{l}-0.003 \\
(0.004)\end{array}$ \\
\hline Some Col. in HSA & $\begin{array}{c}-0.005^{*} \\
(0.003)\end{array}$ & $\begin{array}{c}-0.005^{*} \\
(0.003)\end{array}$ \\
\hline med. HH Earn in HSA & $\begin{array}{c}0.000 \\
(0.000)\end{array}$ & $\begin{array}{c}0.000 \\
(0.000)\end{array}$ \\
\hline Residency Program & $\begin{array}{c}0.025 \\
(0.037)\end{array}$ & $\begin{array}{c}0.025 \\
(0.037)\end{array}$ \\
\hline county FE & yes & yes \\
\hline service FE & yes & yes \\
\hline service-specific output & yes & yes \\
\hline Observations & $196 \mathrm{k}$ & $227 \mathrm{k}$ \\
\hline
\end{tabular}

OLS and Heckman models with dependent variable of natural log of the percent of costs that are expended on outside contracts. All regressions include county fixed-effects, service fixed-effects. Standard errors, clustered by hospital, in parentheses. $* * * p<0.01, * * p<0.05, * p<0.10$. Dependent variable excludes all physician services costs, regardless of contracting type. 
percentage points less intensely than similarly-situated for-profit hospitals.

The hospital-level control variables relate to outsourcing in the ways we might expect. Larger hospitals, either in terms of number of services or discharges, outsource less intensely on average. Neither patient mix nor having a residency program is associated with outsourcing intensity. Demographic variables are only rarely significant in the either of these regressions, likely because most important differences are already controlled for with county fixed effects. Since this will be generally true throughout, we will not always report these coefficients.

\subsection{Prediction 2: Outsourcing and Bias-Intensive Services}

Our model of outsourcing behavior implies that differences between nonprofits and for-profits should be more pronounced in services where control over the services is particularly important to the manager. The difference between nonprofit and for-profit outsourcing behavior should increase in the importance of production bias. Here, we use the services described in Section 3.3, where physicians are the elite workers in the hospital setting. We also investigate labor-intensive services which may have particular importance to elected officials, regulators, or unions. (Alesina et al. 2000, Clark and Milcent 2011).

Table 5 presents the results on Prediction 2 for variants of Equation (1), where ownership type is interacted with an indicator for whether the service is physician-intensive (in column (1)) or labor-intensive (in column (2)). The coefficients on the non-interacted ownership dummies represent the relationship between ownership and outsourcing for non-intensive services, while the sum of the coefficients on the interacted and non-interacted dummies represent the relationship for intensive services. The second prediction of our model states that if physician-intensity is a good proxy for the importance of control to elite workers (pace labor intensity), we should see bigger differences in outsourcing for the physician-intensive services. We discuss each service and ownership type in turn.

Consider, first, the results for physician-intensity in Column (1). There are no statisticallysignificant differences in outsourcing of non-physician-intensive services between private nonprofits and their for-profit couterparts. District hospitals outsource slightly less in these services. The local hospitals, by contrast, outsource even non-physician-intensive services at much lower rates than all other ownership types. For physician-intensive services, by contrast, all three types of nonprofits outsource much less intensely than their for-profit counterparts, and the differences range from about 22 percent for the private nonprofits and district hospitals, to over 60 percent for the local public hospitals. The differences are statistically significant and large. As our model predicts, the difference in outsourc- 
Table 5: Outsourcing Differential by Physician- and Labor-Intensity

(1) (2)

\begin{tabular}{|c|c|c|}
\hline & Physician & Labor \\
\hline Non-Profit & $\begin{array}{l}-0.058 \\
(0.045)\end{array}$ & $\begin{array}{c}-0.070 \\
(0.045)\end{array}$ \\
\hline District & $\begin{array}{c}-0.115^{*} \\
(0.070)\end{array}$ & $\begin{array}{l}-0.098 \\
(0.068)\end{array}$ \\
\hline Local & $\begin{array}{c}-0.350^{* * *} \\
(0.087)\end{array}$ & $\begin{array}{c}-0.343^{* * *} \\
(0.084)\end{array}$ \\
\hline Non-Profit x Physician Intensive & $\begin{array}{c}-0.162^{* * *} \\
(0.061)\end{array}$ & \\
\hline District $\mathrm{x}$ Physician Intensive & $\begin{array}{l}-0.085 \\
(0.094)\end{array}$ & \\
\hline Local x Physician Intensive & $\begin{array}{c}-0.253^{*} \\
(0.136)\end{array}$ & \\
\hline Non-Profit x Labor Intensive & & $\begin{array}{l}-0.082 \\
(0.065)\end{array}$ \\
\hline District $\mathrm{x}$ Labor Intensive & & $\begin{array}{c}-0.255^{* *} \\
(0.099)\end{array}$ \\
\hline Local x Labor Intensive & & $\begin{array}{c}-0.391^{* *} \\
(0.181)\end{array}$ \\
\hline Hospital Controls & yes & yes \\
\hline HSA Controls & yes & yes \\
\hline county FE & yes & yes \\
\hline service FE & yes & yes \\
\hline service-specific output & yes & yes \\
\hline Observations & $196 \mathrm{k}$ & $196 \mathrm{k}$ \\
\hline
\end{tabular}

Dependent variable is the natural log of the percent of costs that are outside contracts. $(d)$ indicates a dummy variable. Standard errors, clustered by hospital, in parentheses. $* * * p<0.01, * * p<0.05, *$ $p<0.10$. Dependent variable excludes all physician services costs, regardless of contracting type. 
ing intensity between nonprofits, both public and private, and for-profits is much larger for physician-intensive services than it is for non-physician-intensive services. The gap in outsourcing intensity is between 9 and 25 percentage points larger for physician-intensive services, although the result is not statistically significant for district hospitals.

The second column of Table 5 shows the results for labor intensity. The literature suggests that labor-intensity may be the bias of interest for hospitals in the public sector, where political considerations may factor into managerial decisions. The pattern of outsourcing differences in the non-labor-intensive services is similar to that for non-physician-intensive services, with small differentials for the private nonprofits and district hospitals but large differentials for the local hospitals. The pattern for labor-intensive services, however, is quite different from what we observed for physician-intensive services. For private nonprofits, outsourcing patterns are not different between non-labor-intensive services versus laborintensive services, given by the small and insignificant interacted coefficient. Both types of public hospitals, by contrast, outsource labor-intensive services at a much lower intensity. The magnitudes of the differential in labor-intensity are quite large, between 26 (district) and 40 (local) percent, and strongly statistically significant.

To sum, the pattern of outsourcing intensity by service-type suggests that, in addition to having different mean levels of outsourcing intensity, the managers of public and private nonprofits are particularly interested in maintaining control of different subsets of services. If we think of outsourcing as a cost-control tradeoff, private nonprofits are maintaining control of services that are physician-intensive, though act quite similar to for-profits for nonphysician-intensive services. Public hospitals also maintain increased control of physicianintensive services, but they continue to outsource even non-physician-intensive services less intensely than for-profits do. The pattern for labor-intensive services is quite different, with only the public hospital especially interested in maintaining control of labor-intensive services. To take a simple example, all three nonprofit firm types maintain (relatively) tighter control of neo-natal intensive care than they do of groundskeeping, but public hospitals also keep a tighter hold on social-work services and skilled nursing care, while private nonprofits do not.

Taken together, these results illustrate three points. First, nonprofit and for-profit responses to physician-intensity and labor-intensity are distinct. Note how this contrast differs from a comparative static exercise of comparing outsourcing rates across services within an ownership types, as Coles and Hesterly (1998), Lopez de Silanes et al. (1997), or Levin and Tadelis (2010) do. We can say not only that nonprofits respond to physician- and laborintensity, but also that they respond for reasons distinct from profit motivation. 
Second, private nonprofit and public responses to non-physician-intensity are also distinct. Whatever is driving the difference between public and for-profit outsourcing rates, it does not seem to be the same thing that is driving the difference between private nonprofit and for-profit rates, or at least it is not the only thing. In our model, the services for which control is important may be different for public hospitals than for private nonprofits, and how public hospitals bias production is not entirely captured by physician intensity. In fact, public hospitals outsource considerably less than private nonprofits for both service bias types, so another factor must be at work.

Finally, nonprofit and public responses to labor-intensity are distinct. Public hospitals are distinctly interested in controlling labor-intensive services, while private nonprofits exhibit no such pattern. Thus, this is not simply a result of a nonprofits' lack of residual claimancy, a feature both types share. There is some evidence that public hospitals are particularly sensitive to labor. Clark and Milcent (2011) find, for example, that public hospitals in France react to rising local unemployment rates by increasing employment, while private nonprofit hospitals show no similar pattern. This is also support for (Andrei Shleifer 1994), where unorganized voters mean public firms are more prone to capture by organized labor and political patronage. We document another effect of public hospitals apparent interest in control of labor-it can lead them to draw the boundaries of the firm in a way that differs from both for-profit firms and private nonprofits.

\subsection{Predictions 3 and 4: Outsourcing After a Fixed-Cost Shock}

The third prediction of the model is, if outsourcing is a tradeoff between cost and control of production, the decisions of nonprofit and for-profit firms should become more similar as budgets tighten. This prediction arises directly from the concavity of the nonprofit's utility from qualifying spending. If there is a large fixed cost shock, the amount available to spend on qualifying spending is relatively low, and the marginal value to the nonprofit firm of an extra dollar is high.

We use a change in regulatory requirements enacted in California in 1994 to capture a fixed-cost shock. This regulation (SB 1953) required short-term general care hospitals in earthquake zones to meet relatively strict engineering standards. The regulation went into effect in 1998, and the first deadline for meeting the loosest standard (no SPC-1, extremely vulnerable, buildings) was January 2008. A stricter standard (no SPC-2, vulnerable, buildings) was mandated for January 2030. For many hospitals, meeting this requirement involved very extensive retrofitting of existing buildings, and most have preferred to construct new buildings, at costs of tens to hundreds of millions of dollars (Meade and Hillestand 2007). 
The hospitals should, thus, have been aware of existence of the shock throughout our sample period, although they may have learned over time about their exact cost.

The actual costs incurred to retrofit or construct new buildings that meet the mandate will be endogenously determined by the firm, but we proxy for the underlying exogenous cost shock by the peak ground acceleration in the location- a measure of earthquake risk (Meade, Kulick and Hillestand 2002). Peak ground acceleration is the maximum fraction of the acceleration of gravity that will occur with a 10-percent probability over the next 50 years; a higher value is more costly. See Chang and Jacobson (2011) for an extensive discussion of the implementation of the mandate, and an overview of the relationship between peak ground acceleration and costs. ${ }^{21}$ The peak ground acceleration of hospitals in our dataset ranges from 0.05 to 1.15. The distribution is centered around the mode of 0.45 and falls off evenly to either side, with a standard deviation of 0.21 . The four ownership types have similar peak ground acceleration average values, about 0.50 .

Table 6 presents the results a variant of Equation (1) in which we interact ownership type with the peak ground acceleration experienced by the hospital. The prediction is that the difference between nonprofit and for-profit hospitals should be most marked when acceleration is small (and the cost shock is least severe). Column (1) presents the results on the full sample of services, while the remaining columns break the services into sub-samples with respect to physician- and labor- intensity.

If differences in outsourcing indeed shrink as budgets tighten, we would expect the greatest difference in outsourcing to occur when there is no cost shock to the hospital's budget. The non-interacted ownership indicators of Table 6 are the predicted difference in outsourcing intensity between the indicated ownership type and a for-profit for a hypothetical hospital that experienced no earthquake risk. In the full sample, regression (1), low-shock private nonprofits outsource between 21 percent less intensely and local hospitals 55 percent less intensely than low-shock for-profit hospitals. To understand the effects of tightening budgets, the interacted coefficients of ownership and acceleration show the direction of change from initial differences as fixed costs increase. The interacted variables all have large positive coefficients, which indicates that the expected outsourcing differential shrinks as the cost shock grows, although none of the interactions are statistically significant in the full sample.

The relationship between Table 6's cost shocks and outsourcing differentials is more clearly seen in figures. Figure 4 shows the predicted outsourcing difference between hospitals of the indicated ownership type and a similarly situated for-profit hospital as a function of the size of the fixed cost shock. The solid line shows the expected difference, and the dotted

\footnotetext{
${ }^{21}$ Chang and Jacobson provided us with this acceleration measure, for which we are very grateful.
} 
Table 6: Outsourcing and Seismic Cost Shocks

\begin{tabular}{lccccc} 
& & \multicolumn{2}{c}{ Physician } & \multicolumn{2}{c}{ Labor } \\
& $(1)$ & $(2)$ & $(3)$ & $(4)$ & $(5)$ \\
& Full Sample & Intensive & Not & Intensive & Not \\
\hline \hline \multirow{2}{*}{ Non-Profit } & $-0.213^{*}$ & $-0.480^{* *}$ & -0.173 & -0.204 & $-0.209^{*}$ \\
& $(0.113)$ & $(0.224)$ & $(0.117)$ & $(0.227)$ & $(0.116)$ \\
District & $-0.255^{*}$ & -0.175 & $-0.263^{*}$ & -0.365 & -0.241 \\
& $(0.145)$ & $(0.254)$ & $(0.153)$ & $(0.238)$ & $(0.154)$ \\
Local & $-0.550^{* *}$ & $-0.974^{* *}$ & $-0.470^{*}$ & $-1.487^{* * *}$ & -0.415 \\
& $(0.262)$ & $(0.431)$ & $(0.259)$ & $(0.567)$ & $(0.262)$ \\
Non-Profit x Acc & 0.256 & $0.759^{*}$ & 0.182 & 0.238 & 0.252 \\
& $(0.214)$ & $(0.442)$ & $(0.216)$ & $(0.433)$ & $(0.218)$ \\
District x Acc & 0.248 & -0.048 & 0.286 & 0.210 & 0.255 \\
& $(0.284)$ & $(0.462)$ & $(0.296)$ & $(0.474)$ & $(0.291)$ \\
Local x Acc & 0.326 & 0.699 & 0.257 & 1.461 & 0.159 \\
& $(0.437)$ & $(0.712)$ & $(0.434)$ & $(0.896)$ & $(0.433)$ \\
Peak Acceleration & -0.142 & -0.604 & -0.068 & -0.373 & -0.107 \\
& $(0.226)$ & $(0.436)$ & $(0.230)$ & $(0.432)$ & $(0.234)$ \\
Hospital controls & yes & yes & yes & yes & yes \\
HSA controls & yes & yes & yes & yes & yes \\
county FE & yes & yes & yes & yes & yes \\
service FE & yes & yes & yes & yes & yes \\
service-specific output & yes & yes & yes & yes & yes \\
$n$ & $194 \mathrm{k}$ & $26 \mathrm{k}$ & $168 \mathrm{k}$ & $22 \mathrm{k}$ & $172 \mathrm{k}$ \\
\hline \hline
\end{tabular}

Dependent variable is the natural log of the percent of costs that are outside contracts, and includes only those observations with positive outsourcing. HSA controls include population, percent black, percent poor, median household earnings, and four educational mix variables. $(d)$ indicates a dummy variable. Standard errors, clustered by hospital, in parentheses. $* * * p<0.01, * * p<0.05, * p<0.10$. Dependent variable excludes all physician services costs, regardless of contracting type. 
lines are 95-percent confidence intervals. A negative number along the vertical axis means that hospitals of the indicated type outsource less intensely than similarly-situated for-profits do. As peak ground acceleration grows, the predicted difference approaches zero for all three ownership types. At the mean peak ground acceleration (0.5), we can strongly reject the null of no difference for the local hospitals, and marginally so for private nonprofits and district hospitals. However, by the time we reach the maximum peak ground acceleration in our sample (1.15), only local hospitals show predicted outsourcing less than for-profit hospitals.

Turning to the service-type subsamples, the final prediction of the model is that, as budgets tighten, outsourcing differences should change the most in high-bias services. Columns (2)-(5) show regressions with interacted ownership type and fixed cost shocks, separating out those services designated "intensive" from the "non-intensive" services for both physicianand labor-intensity. In the physician columns, the two sets of non-interacted coefficients predict behavior in the absence of cost-shocks. We again see support of Prediction 2, that private nonprofits are much less likely to outsource services with high physician-intensity, and local hospitals are less likely to outsource any service. As the cost shock grows, however, private nonprofits start to outsource these physician-intensive services, as shown by the large positive coefficient (0.8) on the interacted variable in column (2). Non-physician-intense services do not see such a change with increasing fixed costs, as evidenced by the small (0.2) and statistically insignificant interacted coefficient in column (3). We present these results graphically in Figure 5. The top figures show the differences in outsourcing between the ownership type and a for-profit as the fixed cost shock increases over the horizontal axis. Notice that private nonprofits and local hospitals both show a clear upward slope that crosses or approaches zero, indicating that as fixed costs grow, the differences shrink. In contrast, the right-hand figures show the relationship between outsourcing for non-physician intense services, where the slopes begin closer to zero and remain fairly flat.

For labor-intensive services, columns (4) and (5) show that, again, local hospitals differentially keep control of most services. However, low-shock local hospitals especially keep control of labor-intensive services (column (4)). Private nonprofits are not differentially responsive to cost shocks for labor intensive services, with similar coefficients in both column (4) and column (5). The interacted coefficients on labor-intensity and peak ground acceleration are positive, suggesting that nonprofits begin to act more like for-profits as fixed costs increase. These coefficients are not significant for the average level of peak ground acceleration. To see the relationship for the range of acceleration values, we present these results graphically in Figure 6. Note local hospitals' steep gradient of the relationship between increasing fixed costs and outsourcing for labor-intensive services, significantly different from zero at low fixed costs. However, the non-labor-intensive service relationship remains flat. 
Throughout, we can find no significant results for district hospitals (although the fullsample results are marginal), perhaps because they make up a relatively small fraction of the hospitals.

The final point to note is that the seismic cost shocks do not seem to be strongly correlated with the outsourcing intensity of the for-profit firms, as the uninteracted effect of peak acceleration is never significant (although in the case of labor- and physician-intensive services, it is quite large). This is consistent with a simple model of the (null) effect of fixed-cost on profit maximization.

\section{Alternative Explanations}

Although we believe that the difference in trade-off between net revenues and production bias induced by the non-distribution constraint is the best explanation of the outsourcing pattern that we observe, we recognize that alternative explanations exist. In this section we consider several leading candidates.

Nonprofits may simply have a bigger in-house production possibility frontier. Maybe the employees of nonprofits are more intrinsically motivated and donate labor, because they agree with the mission, which lowers the cost of performing services in-house. Maybe the tax advantages lower the real cost of in-house production. But if this story is driving the observed patterns, why do nonprofits' outsourcing decisions conform more with for-profits when times are tough? If it is simply a difference in production constraints, and not a difference in the marginal willingness-to-substitute between cost and production bias, we should see for-profit and nonprofit firms respond similarly to fixed-cost shocks, but they do not.

Alternatively, outsourcing could involve a non-monetary management effort. The firm uses costly time and expertise to go out and cultivate a good relationship with a service provider. Since money is less valuable than time or effort to nonprofits, relative to the for-profit (on the margin), nonprofits are less likely to want to make this investment in provider relationships. This story could be captured in our model, where the production bias here is simply managerial effort slack. This alternative explanation could emerge from the exemption of teaching hospitals from the prohibition of directly employing physician labor. If teaching hospitals are more likely to be nonprofit, this may lead to less contracting experience disproportionately for nonprofits. This interpretation of management effort is inconsistent with the data, however, at least for private nonprofits, because this inexperience/managerial slack would have to manifest itself only in selective portions of the hospital's contracting of 


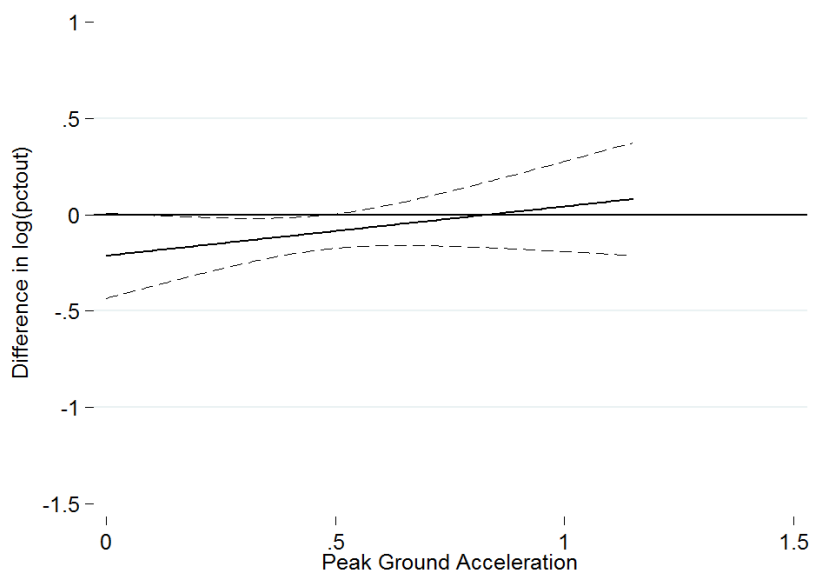

(a) Nonprofit

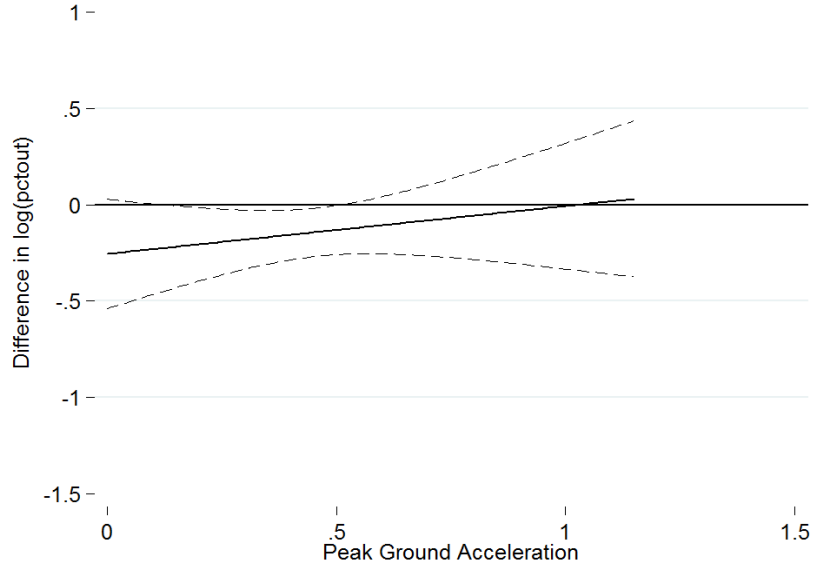

(b) District

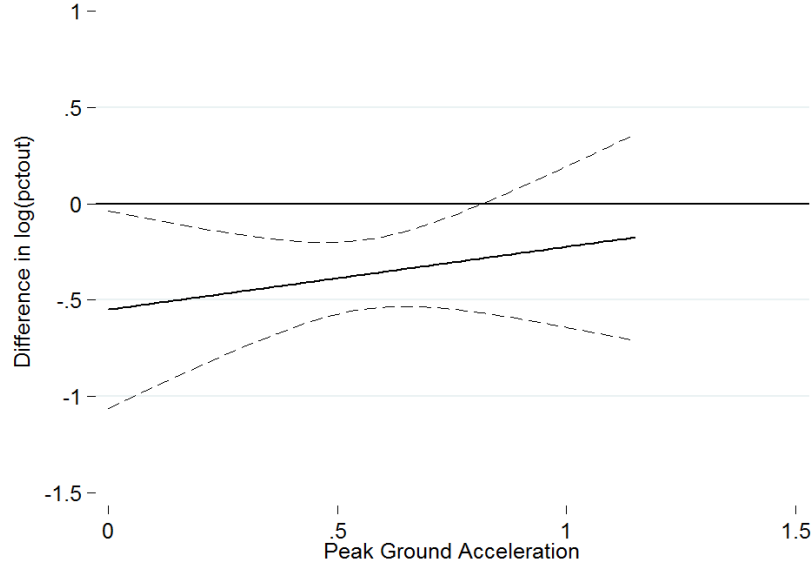

(c) Local

Figure 4: Intensive Margin Ownership Effects as Function of Cost Shocks 


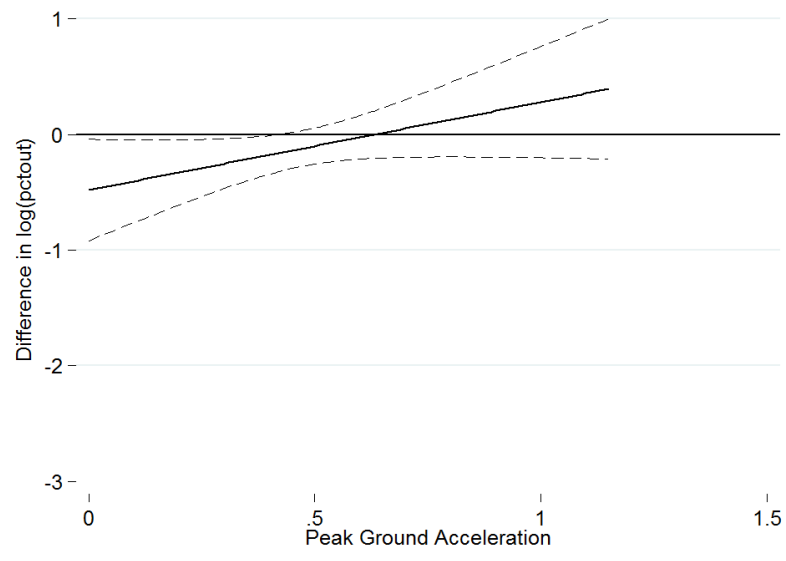

(a) Nonprofit, Physician-Intense

1

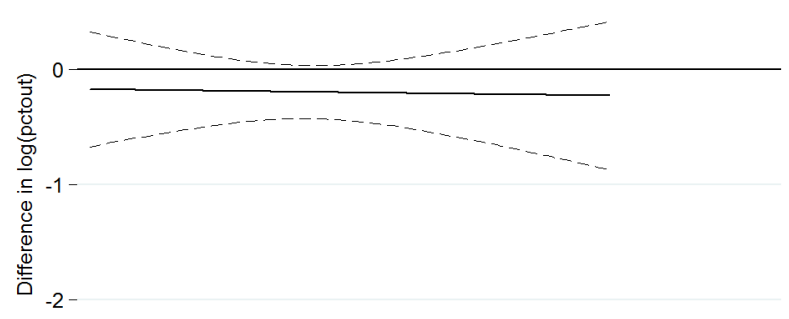

${ }^{-3-}$

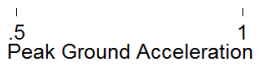

(c) District, Physician-Intense

1

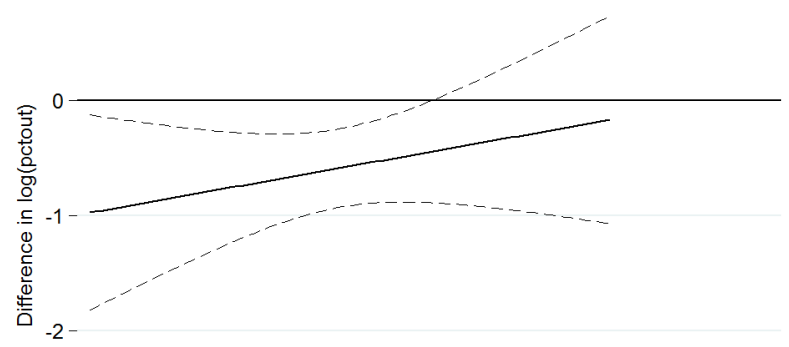

$-3-$
0

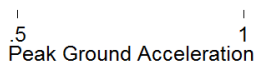

(e) Local, Physician-Intense

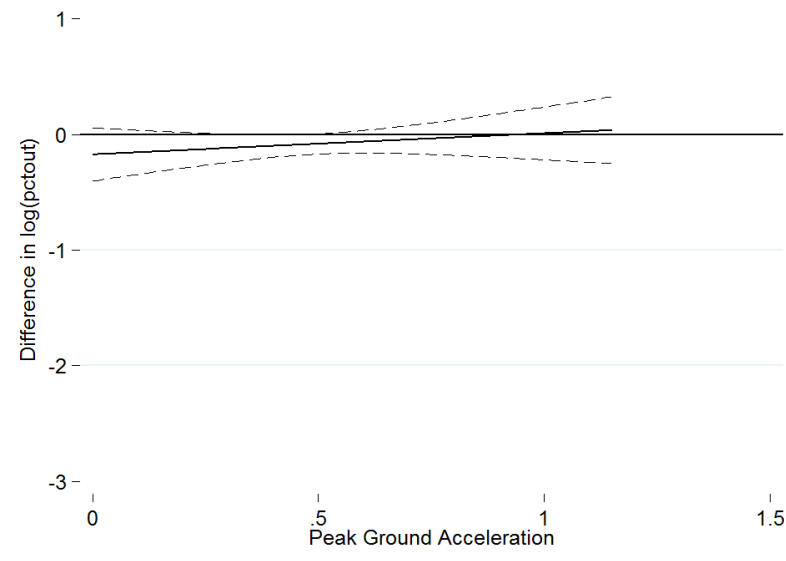

(b) Nonprofit, Non-Physician-Intense

1

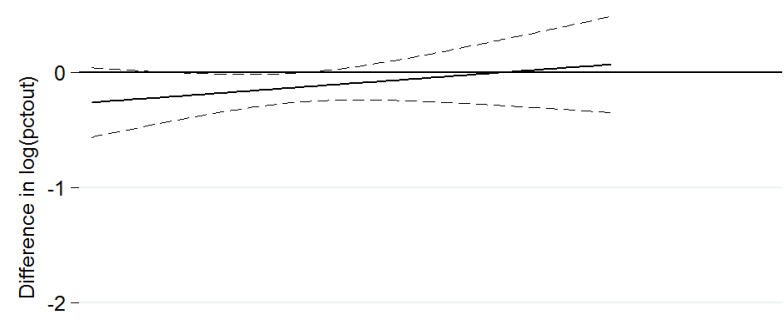

$-3-$
0

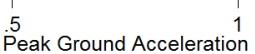

1.5

(d) District, Non-Physician-Intense

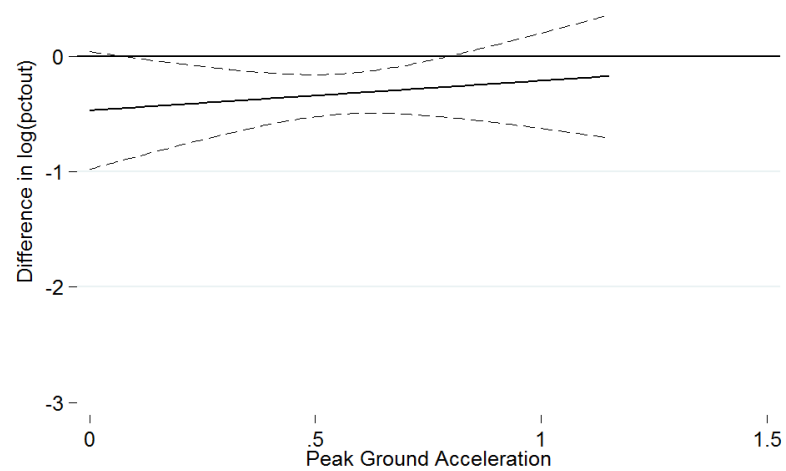

(f) Local, Non-Physician-Intense

Figure 5: Ownership Effects as Function of Cost Shocks and Physician-Intensity 


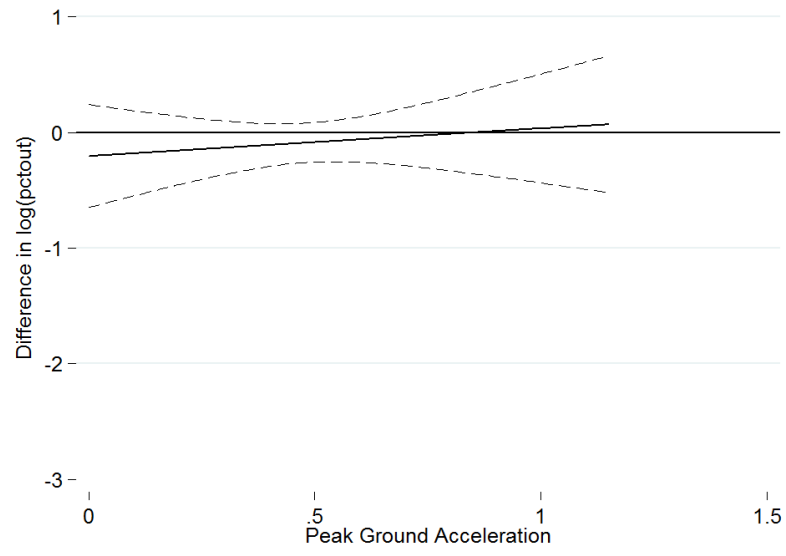

(a) Nonprofit, Labor-Intense

$$
1-
$$

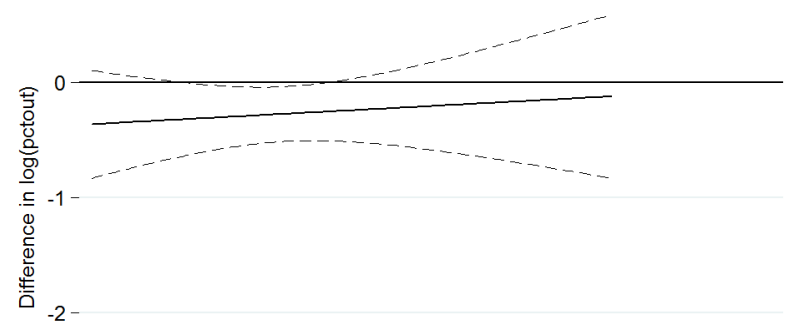

$-3-$

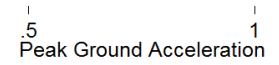

(c) District, Labor-Intense

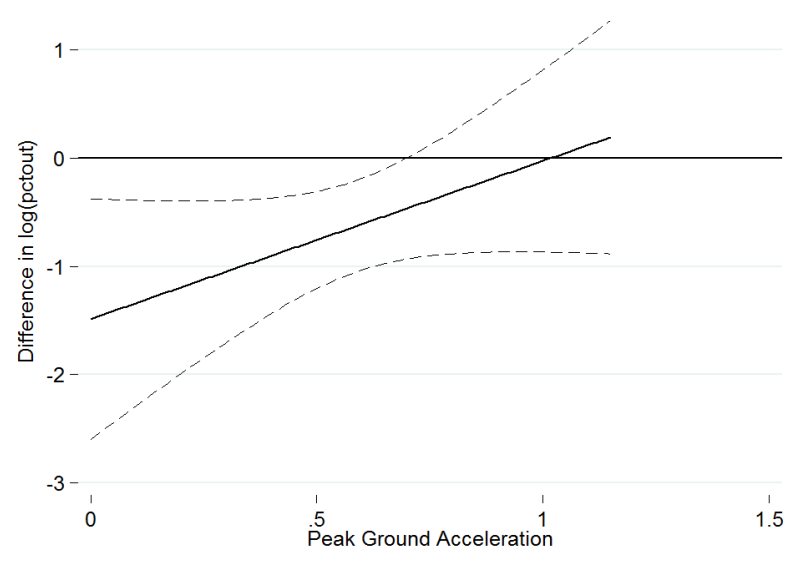

(e) Local, Labor-Intense

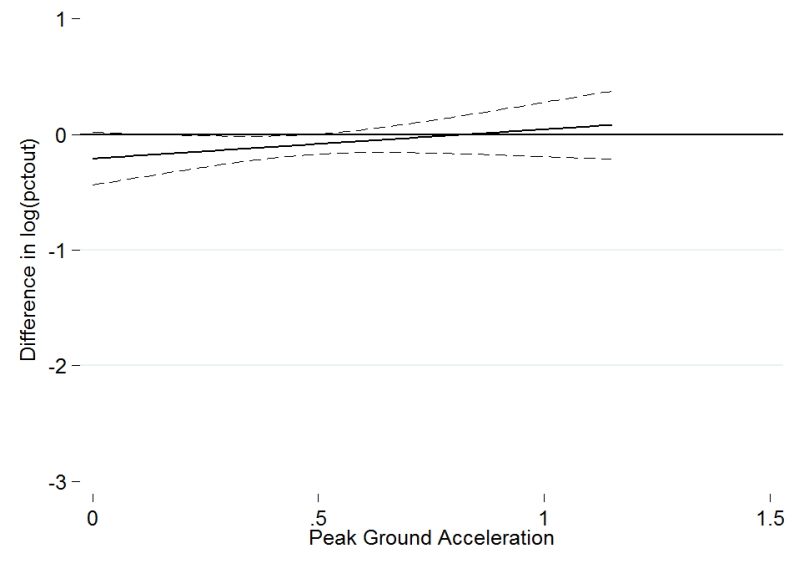

(b) Nonprofit, Non-Labor-Intense

1

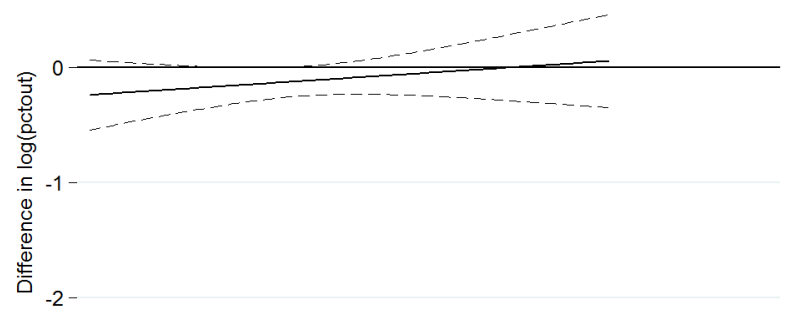

$-3-$

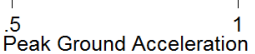

1.5

(d) District, Non-Labor-Intense

1

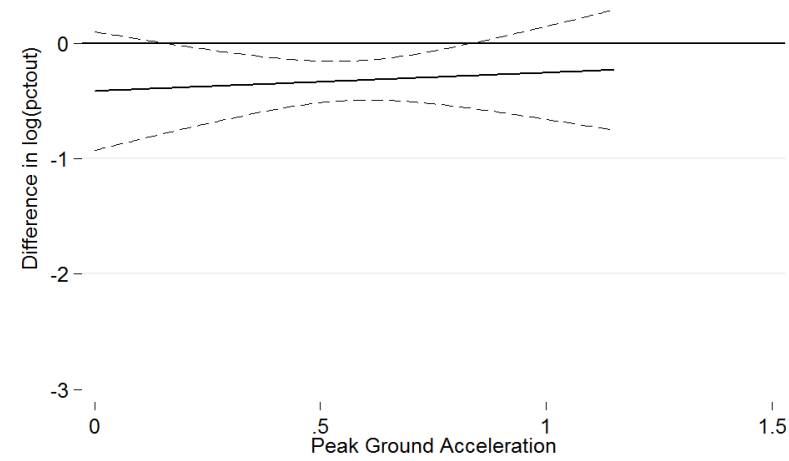

(f) Local, Non-Labor-Intense

Figure 6: Ownership Effects as Function of Cost Shocks and Labor-Intensity 
services outside of physician employment. In the data, nonprofits seem just as willing as for-profits to put in the managerial effort to outsource non-physician-intensive services, like grounds and maintenance or accounting services.

One other difference between nonprofits and for-profits that we have not explored is the firm's ability to access credit markets. Since nonprofits are not able to issue equity, they have a restricted set of instruments available to generate cash. If nonprofits have a hard time getting trade credit from suppliers, they may prefer the constant, certain cost of employment over the fluctuating costs of contracting. This explanation, however, is inconsistent with the attractiveness of outsourcing increasing as the budget gets tighter and free cash, presumably, declines. If doing services in-house minimizes cash demands, nonprofits should bring even more services in-house when a cost shock makes cash even more valuable. We observe the opposite.

A related concern is that nonprofits garner a significant fraction of their capital from endowments, financed by donors. Maybe donors like to buy capital goods, rather than fund contracts to outside providers. Once the capital is in place, the benefit of outsourcing the labor, alone, is small. However, this explanation is inconsistent with the pattern we see in the outsourcing of labor-intensive services. For public hospitals, we know that labor-intensive services are relatively less intensively outsourced, but for private nonprofits there seems to be no difference in relative outsourcing between labor-intensive and non-labor intensive services. These patterns suggest that the labor/capital mix has little to do with outsourcing decisions (in the private nonprofit case) or goes the "wrong way" (in the public case).

Finally, there could be a sample selection story. Maybe some services are profitable for a small hospital to offer only if outsourcing opportunities exist. Nonprofits offer these services whether the services are profitable or not, while for-profits only offer them if they are profitable (Horwitz 2007). If this were the case, we would see these particular services being differentially done in-house by nonprofits, even though if all hospitals offered them, outsourcing rates would be similar. To check this, we limit our investigation to a subsample of services that are offered by nearly all hospitals, yet the size/significance of the relationships we identify are quite similar. If the outsourcing patterns were mostly a selection story, we should see these differences get much smaller in the non-selected sample.

\section{Conclusion}

We find that private nonprofit, public, and for-profit hospitals consistently and significantly differ in the extent to which they outsource services. Controlling for a variety of poten- 
tial confounders, nonprofit and district hospitals outsource less than for-profits, and local hospitals outsource least of all. The difference between nonprofits and for-profits seems to be driven by services for which control of the manner of production is particularly important. The sort of services for which control is important seems to differ between public and private nonprofits, however. Finally, all types of nonprofit hospitals come to look more like for-profits if they are hit with a large fixed-cost shock, such as an expensive seismic retrofitting requirement. For the private nonprofits, all of these results are consistent with a model in which a non-distribution constraint leads nonprofits to trade off between costs and control at a different rate than for-profits do. The private nonprofit differential seems to be driven primarily by physician-intensive services, suggesting the elite workers may be influencing managers to keep control of the services that are important to them, but that does not seem to be the complete story for local public hospitals. Instead, it looks like public hospitals also prefer to conduct labor-intensive services in house, suggesting the public managers (are induced to) value control over labor per-se. All these differences are tested on services excluding physician costs, so differences in behavior are from choices outside of physician contracting legislation.

These findings shed new light on two literatures: the determinants of the make-or-buy decision in organizations other than traditional profit-maximizing firms and the differential behavior of nonprofit versus for-profit versus public firms.

We provide the first empirical demonstration that there is an economically significant divergence between the way for-profit firms draw their firm boundaries and the way that similarly-situated nonprofit and public firms do. This difference occurs both in terms of levels and in terms of how the boundaries move in response to cost shocks. Furthermore, it is not simply a difference between nonprofit and for-profit firms, because the difference between public nonprofits and private nonprofits is just as big as the difference between private forprofits and private nonprofits. In brief, if we think about outsourcing as a tradeoff between cost and control over the manner of production, nonprofits seem to value cost relatively less and control relatively more, at least as long as the nonprofit is not too close to its shut-down constraint. One way of putting the public hospitals into this story is that they value control over production much more than they value costs, especially for tasks that are labor-heavy.

The extent to which models of outsourcing behavior derived in the for-profit context can be directly applied to the decisions of public and nonprofit organizations depends on the economic circumstances in which these organizations find themselves. When firms' budgets are relatively tight, nonprofit firms seem to make outsourcing decisions in much the same way as for-profit firms do. But when nonprofit firms are far from their shut-down constraint they seem to deviate more strongly from for-profits. 
Second, we provide new evidence about other dimensions of production differences across ownership types. Nonprofits not only provide a broader range of services (Horwitz 2007), they perform a larger fraction of those services themselves. Finally, consistent with much of the literature (Chang and Jacobson 2011, Duggan 2002), we find that the three ownership types react very differently to economic shocks. In particular, nonprofits and for-profits react quite similarly along the extensive margin (much like they do along the shut-down margin (Chang and Jacobson 2011)), but react very differently along the intensive margin. This is more evidence that nonprofits act very much like budget-limited consumers, and not like unconstrained profit maximizers.

\section{References}

Alesina, Alberto, Reza Baqir, and William Easterly, "Redistributive Public Employment," Journal of Urban Economics, 2000, 48, 219-241.

Bajari, Patrick and Steven Tadelis, "Incentives Versus Transaction Costs: A Theory of Procurement Contracts," RAND Journal of Economics, 2001, 32, 387-407.

Balakrishnan, Ramji, Leslie Eldenburg, Ranjani Krishnan, and Naomi Soderstrom, "The Influence of Instituional Constraints on Outsourcing," Journal of Accounting Research, 2010, 48, 767-794.

Ballou, Jeffrey P. and Burton A. Weisbrod, "Managerial Rewards and the behavior of for-profit, governmental, and nonprofit organizations: Evidence from the hospital industry," Journal of Public Economics, 2003, 8\%, 1895-1920.

Brown, Trevor and Matthew Potoski, "Transaction Costs and Institutional Explanations for Government Service Production Decisions," Journal of Public Administration Research and Theory, 2003, 13, 441-68.

Chang, Tom and Mireille Jacobson, "What do Nonprofit Hospitals Maximize? Evidence from California's Seismic Retrofit Mandate," 2011. Working Paper, 2011.

Clark, Andrew E. and Carine Milcent, "Public Employment and Political Pressure: The Case of French Hospitals," Journal of Health Economics, 2011, 30, 1103-12.

Coles, Jerilyn W. and William S. Hesterly, "The impact of firm-specific assets and the interaction of uncertainty: an examination of make or buy decisions in public and private hospitals," Journal of Economic Behavior and Organization, 1998, 36, 383-409. 
David, Guy and Arthur J. Chiang, "The determinants of public versus private provision of Emergency Medical Services," International Journal of Industrial Organization, 2009, 27, 312-19.

Deneffe, Daniel and Robert T. Masson, "What do nonprofit hospitals maximize?," International Journal of Industrial Organization, 2002, 20, 461-92.

Duggan, Mark, "Hospital market structure and the behavior of not-for-profit hospitals," The RAND Journal of Economics, 2002, 33, 433-46.

Eggleston, Karen, Yu-Chu Shen, Joseph Lau, Christopher Schmid, and Jia Chan, "Hospital Ownership and Quality of Care: What explains the different results in the literature?," Health Economics, 2008, 17, 1345-1362.

Glaeser, Edward, "Introduction," in Edward L. Glaeser, ed., The Governance of Not-ForProfit Organizations, NBER, 2003, chapter 1.

Glaeser, Edward L. and Andrei Shleifer, "Not-for-profit Entrepreneurs," Journal of Public Economics, 2001, 81, 99-115.

Hart, Oliver, Andrei Shleifer, and Robert Vishny, "The Proper Scope of Government: Theory and an Application to Prisons," Quarterly Journal of Economics, 1997, 112, $1127-61$.

Heckman, James J., "Sample Selection Bias as a Specficiation Error," Econometrica, 1979, 47, 153-61.

Horwitz, Jill R., "Does Nonprofit Ownership Matter," Yale Journal of Regulation, 2007, 24, 139-204.

and Austin Nichols, "Hospital ownership and medical services: Market mix, spillover effects, and nonprofit objectives," Journal of Health Economics, 2009, 28, 924-37.

Iossa, Elisabetta and David Martimort, "Risk Allocation and the costs and benefits of public-private partnerships," The RAND Journal of Economics, 2012, 43, 442-74.

Lafontaine, Francine and Margaret Slade, "Vertical Integration and Firm Boundaries: The Evidence," Journal of Economic Literature, 2007, 45, 629-85.

Levin, Jonathan and Steven Tadelis, "Contracting for Government Services: Theory and Evidence from U.S. Cities," The Journal of Industrial Economics, 2010, 53, 507541. 
Lopez de Silanes, Florencio, Andrei Shleifer, and Robert Vishny, "Privatization in the United States," The RAND Journal of Economics, 1997, 28, 447-71.

Malani, Anup, Tomas Philipson, and Guy David, "Theories of firm behavior in the nonprofit sector: A synthesis and empirical evaluation," in Edward L. Glaeser, ed., The Governance of Not-For-Profit Organizations, Chicago: University of Chicago Press, 2003.

Martimort, David and Jerome Pouyet, "To Build or Not to Build: Normative and Positive Theories of Public-Private Partnerships," International Journal of Industrial Organization, 2008, 26, 393-411.

McClellan, Mark B. and Douglas O. Staiger, "Comparing Hospital Quality at ForProfit and Not- for-Profit Hospitals," in David M. Cutler, ed., The Changing Hospital Industry, Chicago: University of Chicago Press, 2000.

Meade, Charles and Richard Hillestand, "SB1953 and the Challenge of Hospital Seismic Safety in California," Technical Report, California HealthCare Foundation January 2007.

_ _ Jonathan Kulick, and Richard Hillestand, "Esimating the Compliance Costs for California SB1953,” Technical Report, California HealthCare Foundation April 2002.

Nelson, Michael A., "Municipal Government Approaches to Service Delivery: An Analysis from a Transaction Cost Perspective," Economic Inquiry, 1997, 35, 82-96.

Pauly, M. and M. Redisch, "The not-for-profit hospital as a physician's cooperative," American Economic Review, 1973, 63, 87-99.

Picone, Gabriel, Shin-Yi Chou, and Frank Sloan, "Are for-profit hospital conversions harmful to patients and to Medicare?," The RAND Journal of Economics, 2002, 33, $507-523$.

Shleifer, Robert W. Vishny Andrei, "Politicians and Firms," The Quarterly Journal of Economics, 1994, 109 (4), 995-1025.

Sloan, Frank, "Nonprofit Ownership and Hospital Behavior," in A. J. Culyer and J.P. Newhouse, eds., Handbook of Health Economics, Volume 1, Elsevier Science, 2000, chapter 21, pp. 1141-1174. 
Sloan, Frank A., Gabriel Picone, Donald H. Taylor Jr., and Shin-Yi Chou, "Hospital ownership and cost and quality of care: Is there a dime's worth of difference," Journal of Health Economics, 2001, 20, 1-21.

\section{Appendix}

\subsection{Proofs}

Lemma 1: $b^{f p} \leq b^{n p} \quad$ The first-order condition for the non-profit's choice of bias is $\rho+$ $v^{\prime}\left(I\left(b^{n p}\right)\right) I^{\prime}\left(b^{n p}\right)=0$, while that for the for-profit is $\rho+I^{\prime}\left(b^{f p}\right) \max \left\{1, v^{\prime}\left(I\left(b^{f p}\right)\right)\right\}=0$. At the non-profit's bias choice, the for-profit's marginal benefit from increasing bias is the same $(\rho)$, while his marginal cost is weakly greater, so he weakly prefers lower bias (strict when $I\left(b^{n p}\right)>\bar{q}$, so the for-profit is using non-qualifying expenditures).

Proposition and Corollary 1 Using the $\bar{I}_{j}(b)$ notation, we know by revealed preference that $\bar{I}_{n p}\left(b^{n p}\right) \leq \bar{I}_{f p}\left(b^{n p}\right)$ and $\bar{I}_{f p}\left(b^{f p}\right) \leq \bar{I}_{n p}\left(b^{f p}\right)$. It follows immediately from the continuity of the indifference curves that there exists a $b \in\left[b^{f p}, b^{n p}\right]$ such that $\bar{I}_{f p}(b)=\bar{I}_{n p}(b)$. Since the nonprofit firm has strictly convex indifference sets, the curves can cross only once (although they will lie on top of each other when $q^{f p}=q^{n p}$ ), yielding uniqueness, and if $b^{f p} \neq b^{n p}$ is must the bias of intersection must lie strictly between them. Once existence and uniqueness are established, the enumerated conditions are immediate. Finally, the condition for outsourcing follows from the definition of $\bar{I}$. The corollary follows from the fact that $\bar{I}_{j}(b) \geq I(b)$, so if the outsourcing production frontier is outside the own-production frontier only when $b<b^{*}$, then for the range of interest $\bar{I}_{n p}>\bar{I}_{f p}$ and for-profits will outsource whenever nonprofits do. The other case is similar.

Proposition 2 For some set of parameters, take some $b<b^{*}$. From Proposition $1, \bar{I}_{n p}(b)-$ $\bar{I}_{f p}(b)>0 . \bar{I}_{n p}(b)$ is defined implicitly by

$$
v\left(\bar{I}_{n p}(b)-F\right)+\rho b=v\left(I_{n p}-F\right)+\rho b^{n p} .
$$

The implicit function theorem allows us to calculate the derivative of $\bar{I}_{n p}(b)$ with respect to F:

$$
\frac{\partial \bar{I}_{n p}(b)}{\partial F}=\frac{v^{\prime}\left(\bar{I}_{n p}(b)-F\right)-v^{\prime}\left(I^{n p}-F\right)}{v^{\prime}\left(\bar{I}_{n p}(b)\right)}<0,
$$


where the sign of the numerator comes from the fact that $v^{\prime}$ is decreasing and $\bar{I}_{n p}(b)>I^{n p}$, since $b<b^{*}<b^{n p}$. Note, we use the envelope theorem here to ignore the effect $F$ through $b_{n p}$. We can perform a similar exercise to calculate the derivative with respect to $\rho$ :

$$
\frac{\partial \bar{I}_{n p}(b)}{\partial \rho}=\frac{b^{n p}-b}{v^{\prime}\left(\bar{I}_{n p}(b)\right)}>b^{n p}-b
$$

where the final inequality holds since $v^{\prime} \leq 1$.

Finally

$$
\frac{\partial^{2} \bar{I}_{n p}(b)}{\partial \rho \partial F}=\frac{\left(\partial b^{n p} / \partial F\right)}{v^{\prime}\left(\bar{I}_{n p}(b)\right)}-\frac{b^{n p}-b}{\left[v^{\prime}\left(\bar{I}_{n p}(b)\right)\right]^{2}} v^{\prime \prime}\left(\bar{I}_{n p}(b)\right)\left(\frac{\partial \bar{I}_{n p}(b)}{\partial F}\right)<0,
$$

since both terms are negative. The first, since $\left(\partial b^{n p} / \partial F\right)<0$ and the second since both $v^{\prime \prime}(\cdot)<0$ and $\left(\frac{\partial \bar{I}_{n p}(b)}{\partial F}\right)<0$ (from equation 3 , above), but $b^{n p}>b$.

Similarly, when $b^{f p} \neq b^{n p}$ (the only time there is any difference in behavior), $\bar{I}_{f p}(b)$ is implicitly defined by

$$
\bar{I}_{f p}(b)-\bar{q}+v(\bar{q})-F+\rho b=I_{f p}-\bar{q}+v(\bar{q})-F+\rho b^{f p}
$$

and can by solved for explicitly as $\bar{I}_{f p}(b)=I_{f p}+\rho\left(b^{f p}-b\right)$. The derivative with respect to $F$ is zero, while the derivative with respect to $\rho$ is $b^{f p}-b$, and the cross-partial is zero. Comparing these derivatives to those derived above for the nonprofit gives the results of the proposition. For $F$, and the cross-partial, it is immediate. For $\rho$, it follows from the fact that $b^{n p} \geq b^{f p}$. 